\title{
Tigris Basin Landscapes: Sensitivity of Vegetation Index NDVI to Climate Variability Derived from Observational and Reanalysis Data
}

\author{
A. S. Alhumaima and S. M. AbDullaev ${ }^{\mathrm{a}}$ \\ ${ }^{\text {a }}$ South Ural State University, Chelyabinsk, Russia
}

(Manuscript received 23 January 2020, in final form 7 October 2020)

\begin{abstract}
The primary aim of this work is to study the response of the normalized difference vegetation index (NDVI) of landscapes in the lower Tigris basin to current global and regional climate variability presented, respectively, by the global circulation indices and monthly temperatures and precipitation extracted from five observational/reanalysis datasets. The second task is to find the dataset that best reflects the regional vegetation and climate conditions. Comparison of the Köppen-Trewartha bioclimatic landscapes with the positions of botanical districts, land-cover types, and streamflow estimates led to the conclusion that only two datasets correctly describe regional climatic zones. Therefore, searching for the NDVI response to regional climate variability requires the use of normalized analogs of temperatures and precipitations, as well as the Spearman rank correlation. We found that March/April NDVI, as proxies of the maximum biological productivity of the regional landscapes, are strongly correlated with October-March precipitation derived from three datasets and January-March temperatures derived from one dataset. We discovered the significant impact of autumn-winter El Niño-Southern Oscillation and winter Indian Oceanic dipole states on regional weather (e.g., all five recent severe droughts occurred during strong La Niña events). However, the strength of this impact on the vegetation was clearly linked to the zonal landscape type. By selecting pairs of the temperature/precipitation time series that best correlated with NDVI at a given landscape, we have built a synthetic climate dataset. The landscape approach presented in this work can be used to validate the viability of any dataset when assessing the impacts of climate change and variability on weather-dependent components of Earth's surface.
\end{abstract}

KEYWORDS: Asia; Teleconnections; Vegetation; Climate classification/regimes; Statistics; Climate variability

\section{Introduction}

The State of the Climate in 2018 by Blunden and Arndt (2019) begins with the worrying fact that every year since the start of the twenty-first century was warmer than the 1981-2010 average. In addition, further alarming sentiments were added by the climate projections of Hoegh-Guldberg et al. (2018), stating that the tendency of the recent warming of $0.2^{\circ} \mathrm{C}$ per decade will continue over the next 30 years, at least. This future climate warming and concomitant climate variability (e.g., Wartenburger et al. 2017) will have a significant impact on agricultural production. For example, the results of Zhao et al. (2017) imply that each $1^{\circ} \mathrm{C}$ of global mean temperature increase will reduce the global production of wheat and maize by $6 \%-7 \%$, rice and soybean by $\sim 3 \%$. Unfortunately, this scenario does not contradict studies of wild and cultural biome sensitivity to contemporary climate variability. In particular, using satellite imaging from the past 14 years, Seddon et al. (2016) have constructed a vegetation sensitivity index for a range of Earth's ecoregions by their response to monthly climate variability. They found that the highly sensitive areas in the northern midlatitudes corresponded to steppes of Russia,

Corresponding author: A. S. Alhumaima, engineer_alisubhi@ yahoo.com

Earth Interactions is published jointly by the American Meteorological Society, the American Geophysical Union, and the Association of American Geographers.
Ukraine, United States, and Canada, which are principal exporters of wheat. It should be noted that the vegetation of subtropical landscapes can respond to the variability of a time scale spanning an entire season. Thus, predicting the growing conditions in the Diyala River basin, a tributary of the Tigris River, Alhumaima and Abdullaev (2019) found that the normalized difference vegetation index (NDVI), measured at the peak of landscape biological productivity, has higher correlation with the precipitation amounts of the entire rainy winter season and with the temperatures of the first quarter of the year, than with corresponding monthly data. It has also been shown that the spatiotemporal NDVI forecasting of the Diyala River basin, which is characterized by the presence of significant differences in the environmental conditions, can be improved by using the zonal landscape type as an additional predictor to the neural network input layer or by creating an individual forecasting model for each of the zonal landscapes delineated by its natural boundaries.

In this study, we followed the landscape definitions of Nikolayev (2006), where the geographical landscape can be seen as a geosystem homogeneous in origin and history of development and holds specific terrain that is indivisible by zonal factors, with a single geological base and uniform local climate, hydrothermal conditions, soils, and ecological communities. Thus, applying the landscape approach to the forecasting of vegetation conditions is a logical consequence to the hypothesis that we developed in which we expected that responses to the climatic variability in similar geosystems will manifest themselves in a similar way and vice versa. In addition, the concept of a landscape as a system implies some 
resistance to external factors, which means that "normal" climate variability will not lead to the destruction of inner landscape links.

The application of the landscape approach to the forecasting of vegetation conditions has many critical issues. We still answer some questions with simple technological solutions. For example, Abdullaev et al. (2010) demonstrated that in the common case of large-scale ecological assessment with a lack of sufficient field information on a landscape's components, the types of landscape can be approximated by combining multiple layers of geographic information systems (GIS) and then contouring landscapes areas by well-defined natural boundaries rather than attempting to resolve the issue of how to define landscape types. Thus, in the present study, these boundaries were extracted easily by arbitrary choosing from several conventional digital maps and datasets. The river basins map was obtained by reprocessing data from the United Nations Economic and Social Commission for Western Asia, Bundesanstalt für Geowissenschaften und Rohstoffe (UN-ESCWA and BGR 2013), the digital elevation map was downloaded from the Ministry of Economy, Trade, and Industry/NASA (2011), the Moderate Resolution Imaging Spectroradiometer (MODIS) land-cover maps described by Latham et al. (2014), ecological maps adapted from Olson et al. (2001), biogeography maps collected by Ghazanfar and McDaniel (2016), and even regional crop statistics of the Central Statistical Organization (2016). As a result, we obtain a regional map with a set of landscape proxy: individual areas of Earth's surface to which information about the environment will be tied. From the point of view of Earth sciences, the practical landscape definition of Abdullaev et al. (2010) may be not justified, but it is permissible from the point of view of neural network forecasting procedure of Alhumaima and Abdullaev (2019), where only the labels of landscapes proxies for which we will provide forecasts are important. By taking the practical definition of landscapes as a basis, we must explain the meaning of our study's headline: "climate variability derived from observational and reanalysis data." There are few global datasets of gridded meteorological variables obtained only by interpolation of in situ direct observations (e.g., Harris et al. 2014, 2020; Willmott and Matsuura 2019) and various reanalysis sets composed from output of different atmospheric models (e.g., Kanamitsu et al. 2002; Dee et al. 2011; Kobayashi et al. 2015; Gelaro et al. 2017). Observational and reanalysis datasets are designed to describe the same variations in the global and regional climate, but due to differences in technologies of creation, two arbitrary selected datasets will contain similar but different time series of meteorological variables. From the perspective of the landscape approach, two simple questions immediately arise.

The first question is as follows: Will observational and reanalysis data generate similar types of bioclimatic landscapes and how much will the classified generic vegetation types reflect real plant communities? In other words, is it possible to use climate norms of temperature and precipitation and their estimates derived from different datasets to describe the real average states of vegetation landscape? This issue is important not only because it is a more comprehensive comparison of datasets, but also because the current climate classifications are the basis to indicating climate change (e.g., Phillips and Bonfils 2015; Fernandez et al. 2017) and assessing the ecology (e.g., Baker et al. 2010).

The second question is as follows: Is it possible to find a dataset with time series of precipitation and temperatures that best reflects (is correlated with) the space-time variability of primary biological productivity of landscapes (NDVI)? This question is more complex than finding a measure of similarity between some meteorological series derived from different datasets and dependent hydrometeorological values, such as the volume of river runoff (e.g., Lorenz and Kunstmann 2012; Essou et al. 2016; Nkiaka et al. 2017; Reichle et al. 2017), snow cover (e.g., Khan et al. 2008; Wegmann et al. 2017), or aerological observation in data-sparse regions (e.g., Bao and Zhang 2019).

The rest of this paper is organized to answer these questions and to outline the prospects of further research. In section 2, after a brief description of data and methods, we describe the environmental condition and vegetation of the area of study-landscapes of the lower Tigris basin. Then, in section 3a, we discuss the differences in bioclimatic landscape types built on the basis of temperatures and precipitation time series presented by 5 gridded datasets and then, in section $3 b$, we assess the representativeness of the precipitation norms based on discharge of five major Tigris tributaries and historical rain gauge data. Section $3 \mathrm{c}$ presents rank correlation analysis between basinbased aggregated NDVI time series and a range of climatic variables, that allowed evaluates NDVI response to global climate variability over the past 17 years. In particular, the atmospheric promoters of seasonal weather favorable/not favorable to vegetation growth have been found. Section $3 d$ presents the discussion of various maps constructed to visualize vegetation response to climate variability of different scales. It is demonstrated that there are groups of landscapes that respond better to certain meteorological time series. Section 4 provides a conclusion on the justification of the two previously mentioned questions and their solution through the landscape approach.

The widespread use of interpolated meteorological observations and reanalysis results leads to the question of the accuracy and reliability of these data. To answer this question, it is necessary to compare this data with some independent observations, which in their spatial-time resolution and quality can be considered as a reference. Obviously, it is not always possible to find such a reference sample. We show that the question of the accuracy and reliability of gridded temperatures and precipitation can be considered from a pragmatic perspective-whether or not these gridded data correspond to mean state and reflect the fluctuations of primary biological productivity of landscapes sensitive to complex seasonal weather.

\section{Data and methods}

\section{a. Gridded meteorological and satellite data}

The eight gridded datasets used in this study are listed in Table 1. All datasets were processed using MATLAB programming language, version $\mathrm{R} 2018 \mathrm{~b}$. The resulted maps were visualized using ArcGIS, version 10.5, whereas time series 
TABLE 1. List of gridded datasets with their sources, abbreviations, and resolutions.

\begin{tabular}{llr}
\hline \hline \multicolumn{1}{c}{ Dataset and source } & Abbreviation & Spatial resolution \\
\hline ASTER Global DEM (Ministry of Economy, Trade, and Industry/NASA 2011) & DEM & $30 \mathrm{~m} \times 30 \mathrm{~m}$ \\
FAO Global Land Cover SHARE (GLC-SHARE) (Latham et al. 2014) & Land cover & $0.05^{\circ} \times 0.05^{\circ}$ \\
CRU-TS4.01 (Harris et al. 2014) & CRU & $0.5^{\circ} \times 0.5^{\circ}$ \\
UD-V5.01 (Willmott and Matsuura 2019) & UD & $0.5^{\circ} \times 0.5^{\circ}$ \\
ERA-Interim (Dee et al. 2011) & ERA & $0.5^{\circ} \times 0.5^{\circ}$ \\
MERRA2 (Gelaro et al. 2017) & MERRA2 & $0.5^{\circ} \times 0.625^{\circ}$ \\
NSEP-DOE AMIP-II Reanalysis (Kanamitsu et al. 2002) & NCEP & $1.88^{\circ} \times 1.90^{\circ}$ \\
MOD13Q1 (Didan 2015) & NDVI & $250 \mathrm{~m} \times 250 \mathrm{~m}$ \\
\hline
\end{tabular}

graphs were constructed in Excel. The first two datasets are the digital elevation map (DEM) and land-cover map, which are shaped based on the boundaries that were extracted from UN-ESCWA and BGR (2013) and used for the description of the study area (Figs. 1-3). Monthly precipitation sums and monthly mean surface air temperature for the period 19812016 were extracted from two gridded observational datasets [CRU and University of Delaware (UD)] and three atmospheric reanalysis datasets (ERA, MERRA2, and NCEP). These data were used in section $2 \mathrm{c}$ for regional climate classification and in combination with the NDVI data (see Table 1 and section $2 \mathrm{~d}$ ) for the correlation and landscape sensitivity analysis, as is described in section $2 \mathrm{e}$.

\section{b. Additional nongridded datasets}

Various nongridded datasets were used in this study to enhance the results of the main analysis. Rivers discharge and basins characteristics extracted from UN-ESCWA and BGR (2013) and from Isaev and Mikhailova (2009) were used to construct Fig. 2 alongside historical rain gauge data from Davis and Binnie (1959) to estimate the "true level" of regional precipitation in section $3 \mathrm{~b}$. The ecological regions adapted from Olson et al. (2001) and biogeography maps of Ghazanfar and McDaniel (2016) are used to describe vegetation types (Table 2 and Fig. 3), which are essential to estimate the bioclimatic conditions of the study area. Annual yields of wheat and barley from the Central Statistical Organization (2016) and data associated with the management of rain-fed and irrigated fields presented by Mazid (2015) are used to confirm the link between NDVI and agricultural vegetation. The global circulation indexes from NOAA digital datasets [e.g., El NiñoSouthern Oscillation (ENSO) from NOAA (2019a); Atlantic multidecadal oscillation (AMO) from NOAA (2019b); North Atlantic Oscillation (NAO) from NOAA (2019c); and Indian Ocean dipole (IOD) from NOAA (2019d)] are used to demonstrate the obvious teleconnections that govern the life cycle of vegetation landscapes.

\section{c. Climate classification}

The Köppen-Trewartha climate classification (KTC) is widely used in climate change research and environmental studies (e.g., Baker et al. 2010; Belda et al. 2014; Phillips and Bonfils 2015; Fernandez et al. 2017; Alhumaima and Abdullaev 2019). Therefore, KTS classification rules were applied to 35 years of monthly precipitation and temperatures time series of the CRU, UD, ERA, MERRA2, and NCEP datasets. First the limit of dryness $R$ in regions with rainy winter seasons was calculated [Eq. (1)]:

$$
R(\mathrm{~mm})=23 T_{a}-640 P_{w} / P_{a}+410,
$$

where $T_{a}$ represents the mean annual temperature, $P_{w}$ is winter (low sun) precipitation (October-March), and $P_{a}$ is the annual amount of rainfall. Then, by comparing $P_{a}$ with the dryness

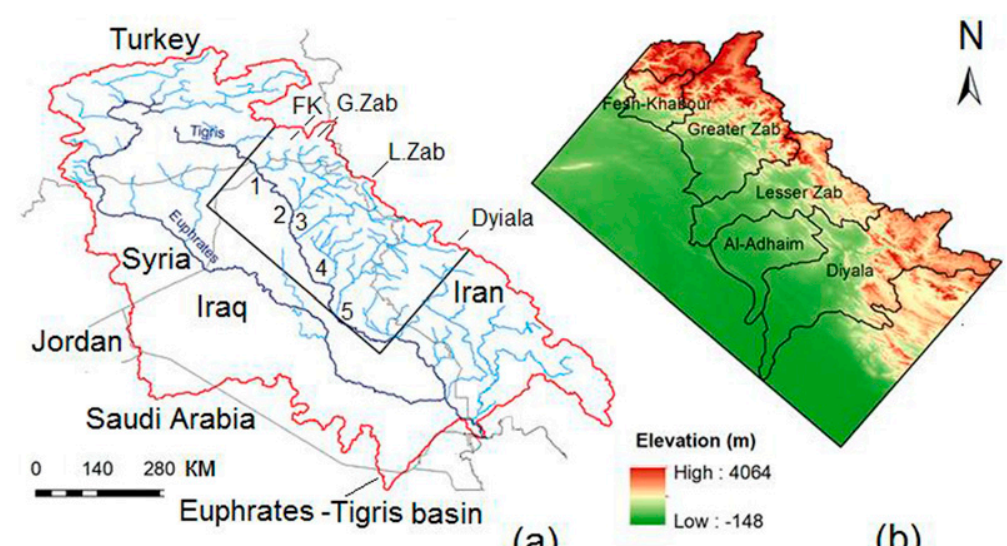

(a)

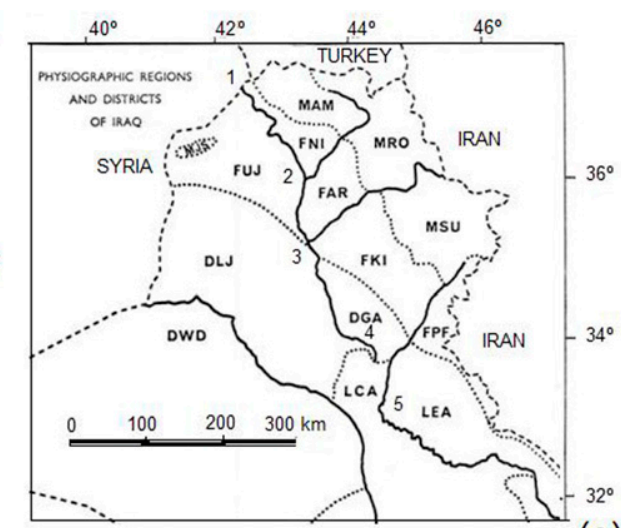

(c)

FIG. 1. Study area: (a) position within the Euphrates-Tigris basin, (b) hypsometry, and (c) physiographic regions of the Iraqi part of the basin (see text). Numbers 1-5 indicate the mouths of Fesh Khabour, Great Zab, Lesser Zab, Al-Adhaim, and Diyala, respectively. 


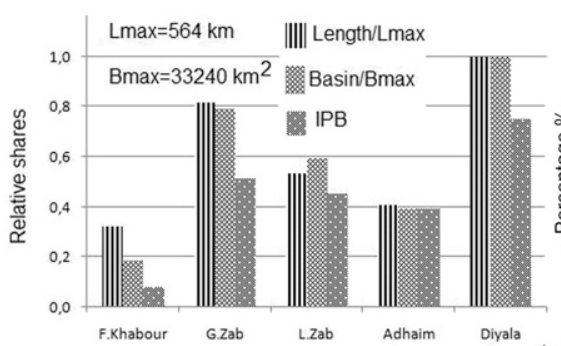

(a)

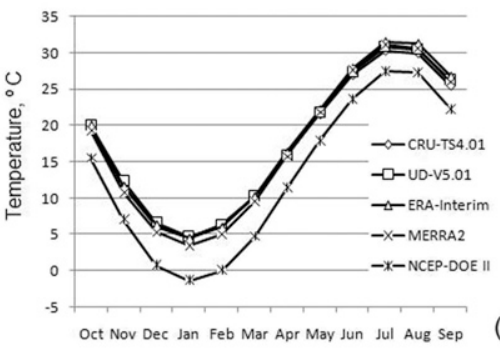

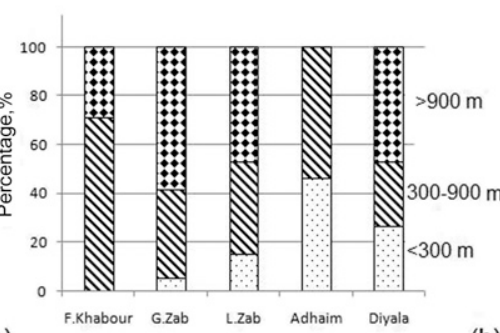

(b)

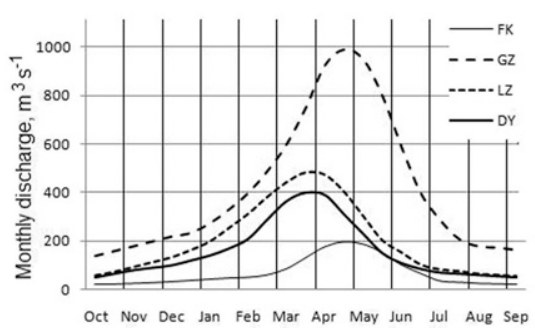

(c)
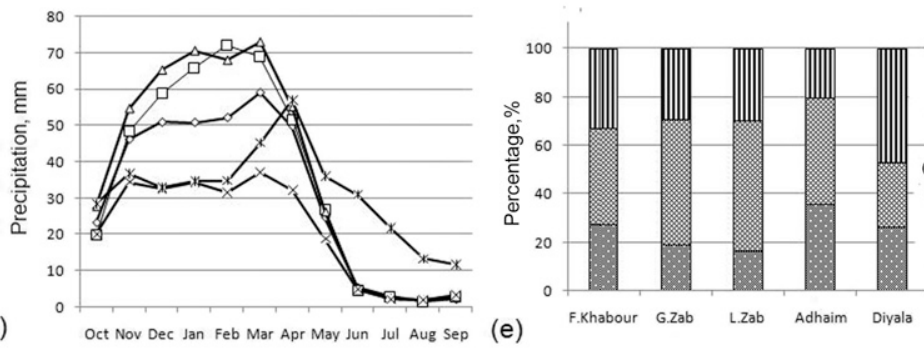

WP

Trees+ +Shrubs - AP Croplands+ + Grasslands LP Sparse vegetation+ +Bare soil

(e)

FIG. 2. (a) The relative river lengths, basin areas, and Iraqi parts of the basins (IPB). (b) Percent of coverage of the basin by plains, foothills, and mountains. (c) Annual courses of river flows (1930-2011). Estimates (1981-2016) of (d) temperatures and (e) precipitation. (f) The estimation of percentages of wild vegetation (WP), agricultural areas (AP), and low productivity areas (LP).

limit $R$ and limit of deserts $R / 2$, two dry bioclimatic types are allocated: the steppe climates (BS), if $R / 2<P_{a}<R$ and the desert climates (BW), if $P_{a} \leq R / 2$. For a further division of moist climates $\left(P_{a} \geq R\right)$, the number of months with temperatures $\geq 10^{\circ} \mathrm{C}$ (N10) was calculated. When $P_{a} \geq R$ and $\mathrm{N} 10 \geq 8$, the climates are treated as subtropical (Cs) with a rainy winter season, whereas when $\mathrm{N} 10 \leq 7$, the climates are related to the temperate continental (DC) types. In the Diyala River basin, based on CRU data, Alhumaima and Abdullaev (2019) found 4 of the 16 main KTC types-BW, BS, subtropical with winter rainy season and dry summer (Mediterranean climate) Cs, and DC - as we moved away from the river mouth to the river head that located in Zagros Mountains. Some additional information related to winter and summer temperature is also included in KTS maps. Examples on using of KTS formulas will be presented on Fig. 4 and Table 3.

\section{d. NDVI images processing}

The two main problems related to the use of NDVI data were resolved: 1) the harmonization of spatial scales between
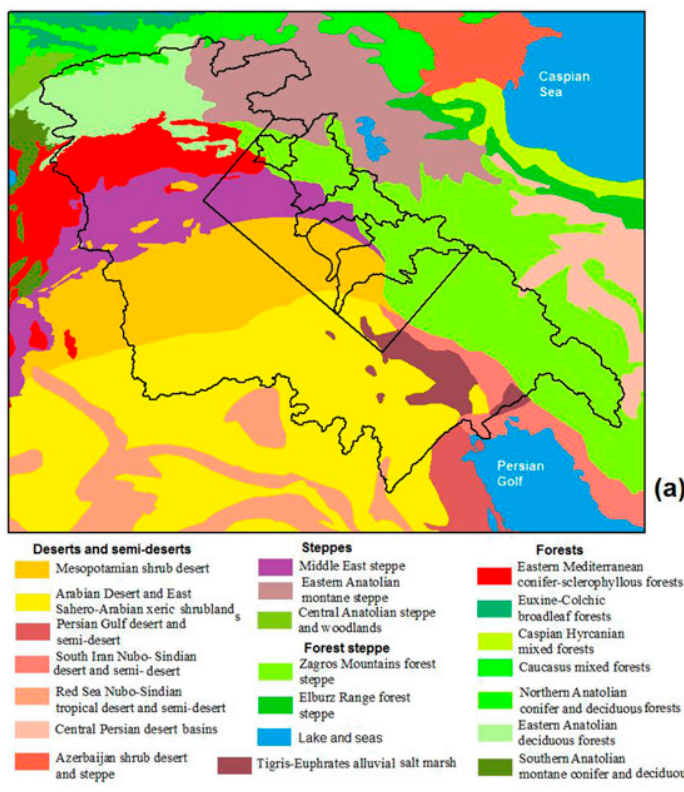
conifer and deciduou
Eastem Anatolian
deciduous forests decicuous forests
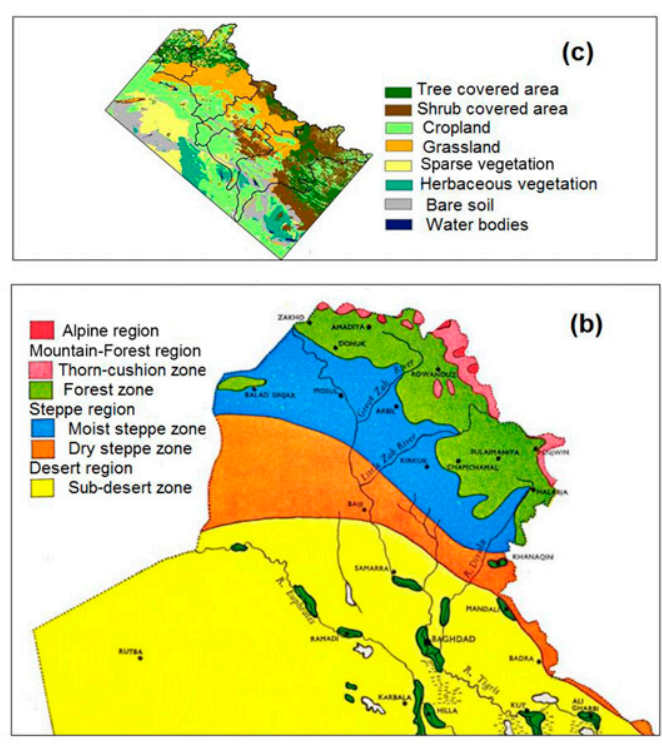

FIG. 3. (a) The natural ecological communities of the Tigris and Euphrates basin. (b) The natural vegetation regions of the IPB. (c) Modern land-use map. 
TABLE 2. Major vegetation zones of the region [adapted from Olson et al. (2001) and Ghazanfar and McDaniel (2016)].

\begin{tabular}{|c|c|c|c|}
\hline Zone & Alt (m) & Main community & Typical plants \\
\hline $\begin{array}{l}\text { Desert, Sahero-Arabian } \\
\text { xeric shrublands, Persian } \\
\text { Gulf semidesert, DLJ, } \\
\text { DGA, LEA, LCA } \\
\text { Mesopotamian shrub } \\
\text { desert }\end{array}$ & $\begin{array}{l}50-500 \\
\quad(<200)\end{array}$ & $\begin{array}{l}\text { Sparse open scrub and } \\
\text { halophytic communities } \\
\text { on sebkha areas } \\
\text { prevalent on saline mud } \\
\text { flats in southwestern Iraq }\end{array}$ & $\begin{array}{l}\text { Haloxylon ammodendron (on moving sand), } \\
\text { Hammadasalicornica, Ziziphus nummulari (in sandy } \\
\text { depressions). Sebkha dominated by Halocnemum } \\
\text { strobilaceum and Aeluropus lagopoides. Subdesert scrub } \\
\text { with Achillea fragrans, Artemisia herba-alba, Astragalus } \\
\text { spp., Centaurea spp., Cousinia stenocephala, Phlomis } \\
\text { bruguieri, and Peganum harmala (on disturbed and waste } \\
\text { ground). Annuals: Stipa capensis (dominant after rain), } \\
\text { Plantago ovata, Astragalus tribuloides etc. }\end{array}$ \\
\hline $\begin{array}{l}\text { Dry steppe, Mesopotamian } \\
\text { shrub desert }\end{array}$ & $\begin{array}{l}300-500 \\
\quad(200-350)\end{array}$ & $\begin{array}{l}\text { Sparse short grassland with } \\
\text { scattered small shrubs }\end{array}$ & Poa bulbosa, Carex stenophylla, Ranunculus asiaticus \\
\hline $\begin{array}{l}\text { Moist steppe, Middle East } \\
\text { steppe, all upper plain } \\
\text { and foothills }\end{array}$ & $\begin{array}{l}500-700 \\
\quad(350-500)\end{array}$ & $\begin{array}{l}\text { Open grassland dominated } \\
\text { by pistachio, almonds, } \\
\text { and other small trees }\end{array}$ & $\begin{array}{l}\text { Protected grassland: Poa bulbosa, Hordeum bulbosum, } \\
\text { Aegilops speltoides, herbs Anemone coronaria, Gundelia, } \\
\text { Cousinia, and Hypericum }\end{array}$ \\
\hline $\begin{array}{l}\text { Zargos forest steppes, all } \\
\text { mountains of Zagros }\end{array}$ & $\begin{array}{l}700-1800 \\
\quad(700-1400)\end{array}$ & $\begin{array}{l}\text { Open to closed forest of } \\
\text { oaks with hawthorn, } \\
\text { pistachios, juniper, and } \\
\text { others in the } \\
\text { undergrowth }\end{array}$ & $\begin{array}{l}\text { Quercus spp. Quercus aegilops, Quercus brantii, Quercus } \\
\text { infectoria, Quercus libani with Pistacia atlantica and } \\
\text { Pistacia khinjuk; in the snow zone: oak-walnut forests } \\
\text { with mulberry, sycamore, oriental, and maple as } \\
\text { subdominants; forests of Pinus brutia var. eldarica }\end{array}$ \\
\hline $\begin{array}{l}\text { Thorn-cushion zones of } \\
\text { Zagros }\end{array}$ & $\begin{array}{r}1700-3000 \\
(>1000)\end{array}$ & $\begin{array}{l}\text { Open shrubland with large } \\
\text { shrubs of milkvetch }\end{array}$ & $\begin{array}{l}\text { Astragalus, associated with Daphne acuminata, Lonicera } \\
\text { arborea, and low thorny shrubs of Acantholimon, } \\
\text { Acanthophyllum, and Cousinia }\end{array}$ \\
\hline $\begin{array}{l}\text { Eastern Mediterranean } \\
\text { forests (eastern part). } \\
\text { West-east } 600-\mathrm{km} \text { belt } \\
\text { ending around Gispre, } \\
\text { Jabal Sinjar }\end{array}$ & $\begin{array}{l}500-1000 \\
\quad(400-600)\end{array}$ & $\begin{array}{l}\text { Broadleaf sclerophyllous } \\
\text { shrublands (maquis) and } \\
\text { dry oak woodlands and } \\
\text { steppe }\end{array}$ & $\begin{array}{l}\text { Artemisia herba-alba, Phlomis bruguieri, Cousinia } \\
\text { stenocephala, Capparis ovata, Teucrium polium, } \\
\text { Scrophulariaxanthoglosa, Phlomis kurdica, Onosma } \\
\text { echinatum, Astragalus platyraphis, and Centaurea } \\
\text { myriocephala; above } 700 \mathrm{~m}, \text { Quercus ithaburensis, } \\
\text { Quercus cerris, Quercus brantii }\end{array}$ \\
\hline $\begin{array}{l}\text { Eastern Anatolian } \\
\text { montane steppes }\end{array}$ & $\begin{array}{l}800-2000 \\
\quad(400-600)\end{array}$ & $\begin{array}{l}\text { Sushionlike and graminoid } \\
\text { formations. Lowlands } \\
\text { support patches of } \\
\text { woodlands, dominated } \\
\text { by oak species }\end{array}$ & $\begin{array}{l}\text { Cushionlike (Artemisia austriaca-Artemisia fragrans, } \\
\text { Astragalus-Acantholimon-Onobrychis); graminoid for- } \\
\text { mations (Stipa } \text { sp., Festuca } \text { sp., Poa bulbosa, Kochia } \mathrm{sp} .)\end{array}$ \\
\hline
\end{tabular}

NDVI and land-cover maps and 2) the choice of a suitable NDVI period for comparison with climate data. The NDVI pixels were spatially averaged and converted into $0.05^{\circ} \times 0.05^{\circ}$ with the simultaneous removal of NDVI pixels that were less than 0.1 to reduce the influence of potentially nonvegetated pixels (bare soil and ice cover). As a consequence, NDVI grids with higher mean values were achieved (Jamali et al. 2014). Thus, each climatology grid of $0.5^{\circ} \times 0.5^{\circ}$, for example, was covered by 100 grids of NDVI and 100 grids of the land-cover map. This resolution is adequate and allowed us to characterize the types of vegetation of each bioclimatic landscape.

The maximum NDVI time for any given natural landscape generally corresponds to the maximum of seasonal green mass productivity. With sufficient soil moisture, the onset of the maximum gross production of the grassland and cropland vegetation depends only on the biological temperatures gained from the moment of mass shoots, while the maximum gross production of forests is achieved after 2-4 weeks from the appearance of tree leaves. Consequently, the maximum NDVI landscape will follow the phenological phases of their vegetation and depend on the weather conditions of the growing season. To compensate for the difference in the growing phases of the different plants, we decided to follow the approach presented in Alhumaima and Abdullaev (2019), wherein one composite image for March (April) consists of the pixels with maximal NDVI value were obtained from two images centered on 6 and 22 March (6 and 22 April). The results below will demonstrate that the composited images of NDVI for March or April are best suited to analyze vegetation's response to the seasonal precipitation and temperature patterns.

\section{e. Time series analysis}

Since the time series of precipitation, temperatures, NDVI, and crop yields have values with significantly different scales, we decided to use the Spearman rank correlation (SRC) analysis as an appropriate method to compensate for the possible nonlinear effects. This is because SRC can assess all types of monotonic relationships, while common Pearson's correlation assesses only linear relationships. To be more confident in the results of analysis and visualization, precipitation and temperature time series were normalized using the standardized precipitation index (SPI) proposed by McKee et al. (1993) and $z$ score with seasonally averaged, respectively. Thus, a 35-yr time series of 6-month SPI (October-March) and 3-month 


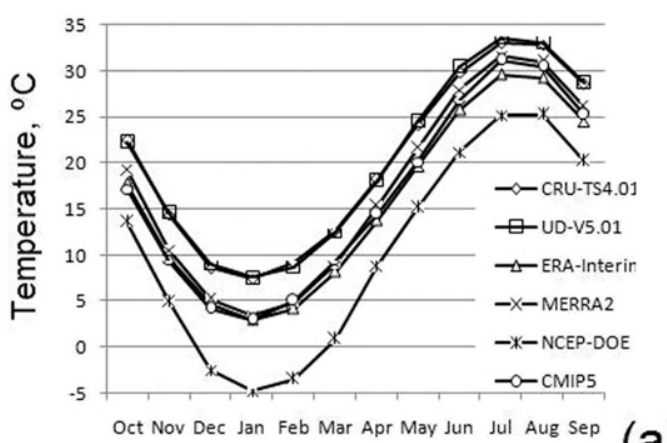

Oct Nov Dec Jan Feb Mar Apr May Jun Jul Aug Sep (a)

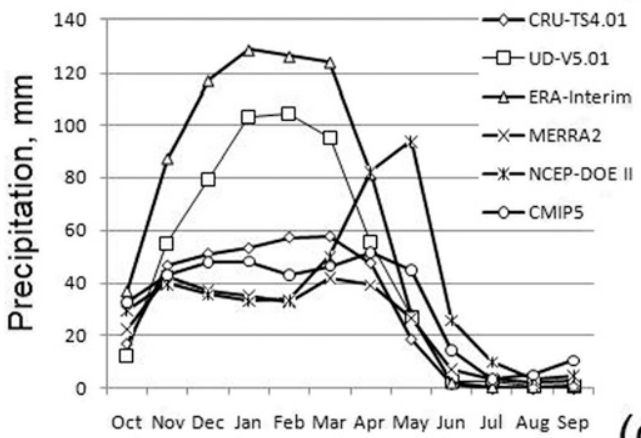

Oct Nov Dec Jan Feb Mar Apr May Jun Jul Aug Sep

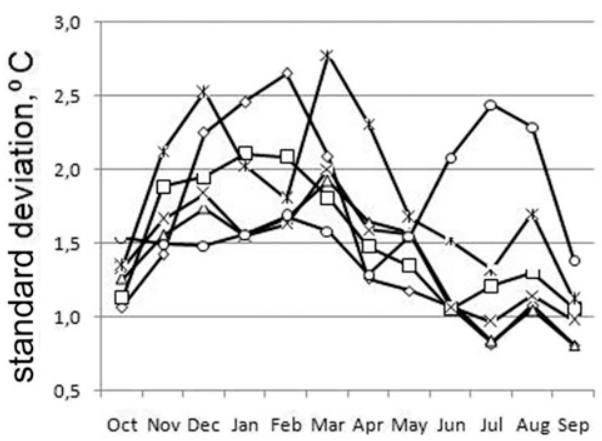

(b)

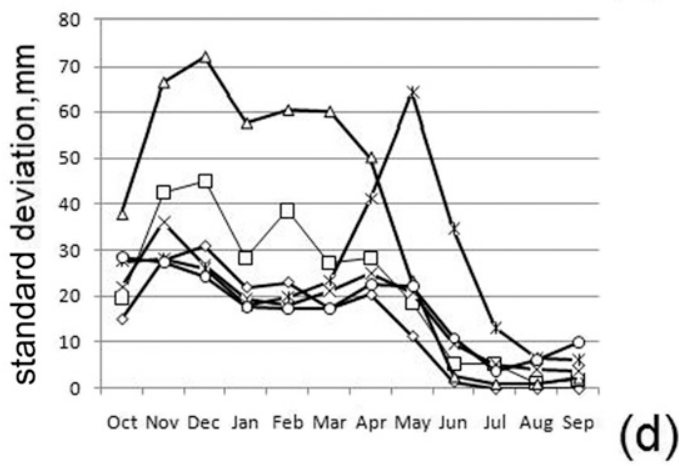

FIG. 4. Monthly (left) mean and (right) standard deviation of (a),(b) temperatures and (c),(d) precipitation of the LZ basin central point near lake Dukan $\left(36^{\circ} \mathrm{N}, 45^{\circ} \mathrm{E}\right)$ according to CRU, UD, ERA, MERRA2, and NCEP (19812016) and CMIP5 ensemble projections for 2020-39 (low-emission scenario).

(January-March) temperature $z$ scores were constructed for each of the five climatic datasets. Alhumaima and Abdullaev (2019) established that 6-month winter precipitation and 3-month mean temperatures are the best predictors of NDVI; this is further established in this study. Some details on the procedures of visualization and averaging of ranked variables will be outlined in the text.

\section{f. Study area}

The aim of this portion of the study was to show the diversity of bioclimatic conditions within the study area contoured by the natural boundaries of the lower Tigris basin. Section $2 f(1)$ examines the environmental conditions of the growth of plant communities discussed in section $2 \mathrm{f}(2)$.

\section{1) ENVIRONMENTAL CONDITIONS}

The Tigris River is fed by waters of numerous tributaries, which originate in the mountains of Zagros in Iran, Iraq, and Turkey. For convenience, we defined the study area as the basins of five major tributaries of Tigris: Fesh Khabour (FK), Greater Zab (GZ), Lesser Zab (LZ), Al-Adhaim (AD), and Diyala (DY), including their mountain headwaters and river mouths along the Tigris course (Fig. 1a). Thus, the study area is located between $38^{\circ} 38^{\prime}$ and $48^{\circ} 07^{\prime} \mathrm{N}$ and $41^{\circ} 05^{\prime}$ and $48^{\circ} 07^{\prime} \mathrm{E}$, occupying about $28 \%$ of the Euphrates-Tigris basin. The total area of the five basins is $98500 \mathrm{~km}^{2}$, where one-third is occupied by the basin of DY and its tributaries with a total length of $564 \mathrm{~km}$ [more information about all basins can be found in
UN-ESCWA and BGR (2013); the climate and vegetation of the DY basin were studied in Alhumaima and Abdullaev (2019)]. Figure 2 shows the comparative characteristics of the river basins. Figure 2a demonstrates that four of the major basins are mainly located in Iraq. This greatly facilitated the data search and made it possible for more spatially accurate analysis of principal wild and cultural biomes from various sources (e.g., Latham et al. 2014; Olson et al. 2001; Ghazanfar and McDaniel 2016; Central Statistical Organization 2016). To make connections with the descriptions of agricultural production, we added the administrative boundaries to the basin boundaries, which often coincided with the natural boundaries of their tributaries. Thus, the upper basins of the GZ (FK) are distributed between the Turkish provinces of Hakkari and Van (Şirnack), while the upper reaches of the LZ and DY are located mainly in Iranian Kurdistan. The middle-to-upper river basins are under the responsibility of provinces of Kurdish autonomy: Dohuk, Erbil, Sulaymānīyah, and Halabja, whereas the lower basins of GZ, FK, LZ, DY, and entire AD basin are under the responsibility of the Iraqi central government provinces: Nineveh, Kirkuk, Saladin, and Diyala. In these eight provinces, rainfed and partially irrigated farmlands cultivated with wheat and barley are widespread (Khalil and Abdullaev 2020).

Linking data to the height zones also helped us understand the structure of the regional landscapes. As Fig. 1b shows, the northeastern contours of the river basins pass through the spurs of Zagros where individual peaks frequently reach $3000 \mathrm{~m}$ or more, while the rivers' estuaries are located on the 
TABLE 3. An example of climate classification at Dukan $\left(36^{\circ} \mathrm{N}, 45^{\circ} \mathrm{E}\right)$.

\begin{tabular}{lcccccccccc}
\hline \hline \multicolumn{1}{c}{ Data } & $T_{a}\left({ }^{\circ} \mathrm{C}\right)$ & $P_{w}(\mathrm{~mm})$ & $P_{a}(\mathrm{~mm})$ & $P_{w} / P_{a}$ & $R(\mathrm{~mm})$ & N10 & Main & T7 & T1 & Subtype \\
\hline CRU & 20.1 & 284.1 & 352.3 & 80.6 & 357.0 & 9 & BS $(\mathrm{Cs})$ & 33.0 & 7.4 & BShk \\
UD & 20.3 & 449.3 & 537.6 & 83.6 & 342.0 & 9 & Cs & 33.6 & 7.6 & Cshk \\
ERA & 15.9 & 620.4 & 734.3 & 84.5 & 234.0 & 8 & Cs & 29.6 & 3.0 & Cshk \\
MERRA2 & 17.2 & 211.3 & 292.4 & 72.3 & 342.6 & 8 & BS & 31.6 & 3.5 & BShk \\
NCEP & 10.4 & 221.2 & 441.1 & 50.1 & 327.9 & 6 & DC & 25.2 & -4.8 & DCho \\
CMIP5 & 16.4 & 262.1 & 392.5 & 66.8 & 360.1 & 8 & Cs & 31.2 & 3.0 & Cshk \\
\hline
\end{tabular}

Mesopotamian plain. From the total catchment area of the rivers, $46 \%$ are mountain regions with heights above $900 \mathrm{~m}$, $32 \%$ are foothills with elevations from 300 to $900 \mathrm{~m}$, and $22 \%$ are plains. According to the topography of the area, the territory of Iraq within the study area can be divided into several regions and districts as shown on Fig. 1c. We will list the Iraqi geographical districts according to Ghazanfar and McDaniel (2016), because they give an idea of the physical and geographical characteristics of the area of study and the diversity of the landscapes studied. In the Mountainous (M) region, the following districts stand out: Amadiya (MAM), Rowanduz (MRO), Sulaymānīyah (MSU), and Jabal Sinjar (MJS). In the Upper Plains and Foothills (F) region: Upper Jazira (FUJ), Nineveh (FNI), Arbil (FAR), Kirkuk (FRI), and Persian Foothills (FPF). The Desert Plateau (D) region is located at the southwest boundaries of the study area and includes Lower Jazira (DLJ), Ghurfa-Adhaim (DGA), and Western Desert (DWD). The lower area of the Diyala watershed is bordered from the southeast by the Lower Mesopotamian (L) region, which includes Eastern Alluvial Plains (LEA) and Central Alluvial Plains (LCA).

The distribution of watersheds' heights shown in Fig. $2 b$ clearly illustrates that the large river basins GZ, LZ, and DY are mainly mountainous, FK river basin is mainly foothills, while $\mathrm{AD}$ river basin is a mixed area of foothills and plains, with less than $1 \%$ of the area above $900 \mathrm{~m}$. The presence of high mountains in the basins is important for the water balance of the region. Figure 2c, adapted from data of UN-ESCWA and BGR (2013), presents the monthly water discharges that were measured at discharge stations located near estuaries of unregulated FK and GZ rivers. For the rivers LZ and DY, the discharge was measured at stations located above reservoirs Dukan and Derbendikhan, respectively. The combined effects of snowmelt as a result of rising temperatures and spring rains (Figs. 2d,e) lead LZ and DY (FK and GZ) to reach peak discharge at the end of March (between the second half of April and the first half of May). Among the five rivers, GZ is the most powerful, and, because of the lack of obstacles in its path, the heavy seasonal rains were immediately transferred by the Tigris River into flooding in Baghdad before the construction of the Samarra Dam in the 1960s.

Before we go on to consider the vegetation of the region, note that the 35-year monthly mean values of precipitation and temperature for the whole region (Figs. 2d,e) that found using traditional averaging of the temporal series explain both the annual water cycle on Fig. 2c and the agricultural cycle. Despite the schematics, Figs. $2 \mathrm{~d}$ and 2e reflect one key feature of the regional climate: during the rainy season from October to April, air temperatures exceed $5^{\circ} \mathrm{C}$ for at least 3 months. Since most of the wild meadow and cultural barley and wheat species begin to vegetate at $+5^{\circ} \mathrm{C}$, which make up the bulk of the green mass in the steppes, savannas, and cultural biocenosis, they have 90-120 days to complete their life cycle when hydrothermal conditions are at their best conditions. Twothirds of farmers sow their wheat during the first and second week of November, while other farmers sow either during October or December (Mazid 2015). According to four datasets, the transition of temperatures through $+10^{\circ} \mathrm{C}$ occurs in March, thus activating most of the woody biomes. The landcover type estimates calculated based on the map of Latham et al. (2014) depict (see Fig. 2f) that 37\%-54\% of the basins are occupied by agricultural productive (AP) area (croplands and grasslands), and $20 \%-37 \%$ can be attributed to wild vegetation (shrubs, forest, and herbaceous vegetation). Therefore, one would expect that at least two-thirds of the region will be covered with green fields, meadows, shrubs, and forest by the end of the rainy season in March-April. This would be the case if we exclude recurrent regional droughts (e.g., Kelley et al. 2015; Muhaimeed and Al-Hedny 2013; Mathbout et al. 2018; Alhumaima and Abdullaev 2018).

\section{2) VEGETATION OF STUDY AREA}

Figure 3 demonstrates a sequence of vegetation maps lined up from the ecological regions and major natural biomes of the Iraqi portion to the land-cover map of the basins to increase their resolution. The maps are adapted from Olson et al. (2001), Ghazanfar and McDaniel (2016) and Latham et al. (2014). The ecological map in Fig. 3a shows that the conditions in most of the upper and middle river basins are favorable to Zagros Mountains forest steppes, making up about $50 \%$ of the basin area. This zone changes to eastern Mediterranean conifer-sclerophyllous broadleaf forests (red) in the west along the Turkish/Syrian borders and it continues to grow in the direction of the Levant, opened to the passage of winter cyclones from Atlantic. This belt is contoured from the south by the socalled Middle East steppes and Mesopotamian shrub deserts. These types of steppes and semideserts, which are part of contemporary Iraq, Syria, and northern Egypt, overlap with the most productive Middle East zones called Fertile Crescent (e.g., Kelley et al. 2015) by the British more than 100 years ago. From the point of view of the physiographical zones of Iraq (Fig. 1c), these steppes are distributed between the foothills districts and are well-aligned with the divisions of the region's natural vegetation of dry and moist steppes (Fig. 3b). 
Economic activity has had a significant impact on the nature of the region. Figure $3 \mathrm{c}$ shows the current land-use conditions. Comparing this figure with maps of vegetation and environmental conditions, you can see that all of the moist steppes are ploughed (Fig. 3c), and that the forest areas move noticeably higher into the mountains, giving way to pastures. Under the current conditions (Ghazanfar and McDaniel 2016), forest communities will not be restored after reduction due to grazing sheep and goats. We also examined various regional internet sources that provided images of the remains of forest vegetation and confirmed that significant areas of contemporary grasslands and croplands are the results of continuous deforestation. Indirectly, these assumptions were supported by comparing the shrub/tree-covered areas in the DY around the basin of Halabja and those in DY tributary around of Iranian Sanandaj, which are located on the same forest zone and exposed to the same climates (Alhumaima and Abdullaev 2019). The small areas of forests around Halabja can be explained by the fact that modern agricultural activity in the region had started more than 50 years ago when the Derbendikhan Dam was constructed, as compared with the Sanandaj, which has large forests, in which agricultural activity began only recently when the Vahdat and Gavoshan Dams were built. The initial deforestation of foothill shrubs in the upper part of the AD river basin can be seen from Fig. 3c, also.

Vegetation highlights of the region (Table 2) were obtained by compiling Olson et al. (2001), Ghazanfar and McDaniel (2016), and other sources. There is a need to clarify and review plant conditions and a description of soil conditions must also be included. For example, in the districts of Rowanduz, Sulaymānīyah, and Nineveh, there are common vertisols (fertile heavy soils) that require rigid water control. The kastanozems of the sagebrush-cereals steppe of the Hakkari intermountain hollow in the upper GZ have similar fertility to vertisols. However, since the main purpose of this work is to assess the landscapes sensitivity to climate variability, this is sufficient - the region is extremely rich in plant resources and reaches full development in early to midspring. Thus, Table 2 demonstrates that conditions of moist steppe and forest steppe are favorable for the growth of wild cereals such as bluegrass Poa bulbosa, barley Hordeum bulbosum, and goat grass Aegilops speltoides. Therefore, many of the foothills and mountainous regions, more frequent in the east Mediterranean steppe; then in the east Anatolian steppe, where precipitations are more distributed during the seasons (Olson et al. 2001) and wild progenitors of cultural varieties of wheat are abundant, are areas of winter wheat production.

\section{Results and discussion}

\section{a. Evaluation of regional climates}

The above description shows that the studied region lies across several bioclimatic zones from mountain temperate climates of the upper rivers to hot deserts in their lowlands. This makes it much easier to further discuss regional climate assessments.

As an example of climate classification according to KöppenTrewartha rules is illustrated in Fig. 4 and Table 3. Figure 4 shows the annual course of precipitation and temperature for the grid point located at $36^{\circ} \mathrm{N}, 45^{\circ} \mathrm{E}$, which roughly corresponds to the position of Lake Dukan on LZ river where its waters are impounded by the Dukan Dam $\left(35^{\circ} 57^{\prime} 15^{\prime \prime} \mathrm{N}, 44^{\circ} 57^{\prime} 10^{\prime \prime} \mathrm{E}, 516 \mathrm{~m}\right)$. The geographical location of this reservoir corresponds to the zone of wet savannas with a transition to the forest steppe of the Zagros; and is actively used for agriculture in Sulaymānīyah and Rowanduz districts (see Figs. 1 and 3).

Figure $4 \mathrm{a}$ demonstrates the significant difference in the 35-yr-based monthly temperatures, where the observations of CRU and UD are consistent with each other, ERA and MERRA2 models show noticeably low temperature values, and the NCEP model shows extremely low winter and mild summer temperatures. The resulting annual temperatures Ta determined from ERA and MERRA2 differed from those of CRU and UD to up $3^{\circ}-4^{\circ} \mathrm{C}$ (Table 3 ), which is an exceptionally large value. For the sake of comparison, the figure includes the climatic forecasts for the near 20 years according to phase 5 of the Coupled Model Intercomparison Project (CMIP5). The 35 models of CMIP5 ensemble climate forecasts are almost identical to the current ERA and MERRA2 temperatures with standard temperature deviations of $1.5^{\circ}-2^{\circ} \mathrm{C}$ (Fig. 4b). Oddly enough, only CMIP5 projections demonstrate the increased variability of the summer temperatures and low variability of winter temperatures. The notion of diverging climate estimates is enhanced by analyzing winter precipitation $P_{w}$ (OctoberMarch). Here, the NCEP and MERRA2 reanalysis models produce slightly smaller $P_{w}$ than those produced based on the CMIP5 forecast and CRU observation (Fig. 4c, Table 3). The proximity of CMIP5 and CRU is expected because the CRU is the unique dataset used for climate model validation (Taylor et al. 2012). On the other hand, ERA and UD unexpectedly show near Dukan winter rainfalls up to 2-2.5 times as great as other datasets.

Let us analyze Table 3. The distinctive feature of climates comparison based on Eq. (1) is the complexity of the assessment. However, you can see that the calculated limits of dryness $R$ for four datasets are within a relatively narrow interval of 330-360 mm. Only with the ERA reanalysis model, was the threshold about $100 \mathrm{~mm}$ smaller.

By comparing the annual precipitation $P_{a}$ with dryness limit $R$ and desert threshold $R / 2$, we obtain two cases of dry BS climates (MERRA2 and CRU) and four cases of humid climates. After counting the months with temperature above $10^{\circ} \mathrm{C}(\mathrm{N} 10)$, three of these four humid climates were Cs and one was DC. Taking the temperature of the hottest and coldest months into account [July (T7) and January (T1), respectively], we obtained very hot steppe climates (BShk), subtropical climates (Cshk), and one temperate cold winter climate (DCho).

At the end of the discussion of Fig. 4, one important detail needs to be taken into account: when comparing the regional climate in the following subsection, the monthly precipitation and temperatures of the same grid nodes had standard precipitation (temperature) deviations with relative variation to up $\sim 50 \%(25 \%)$ according to the different datasets. However, such interannual fluctuations in contemporary datasets often exceed the deviation of the ensemble forecasts of CMIP5.

We did not expect that Cs climates would not appear in climate classification maps based on MERRA2 and NCEP 


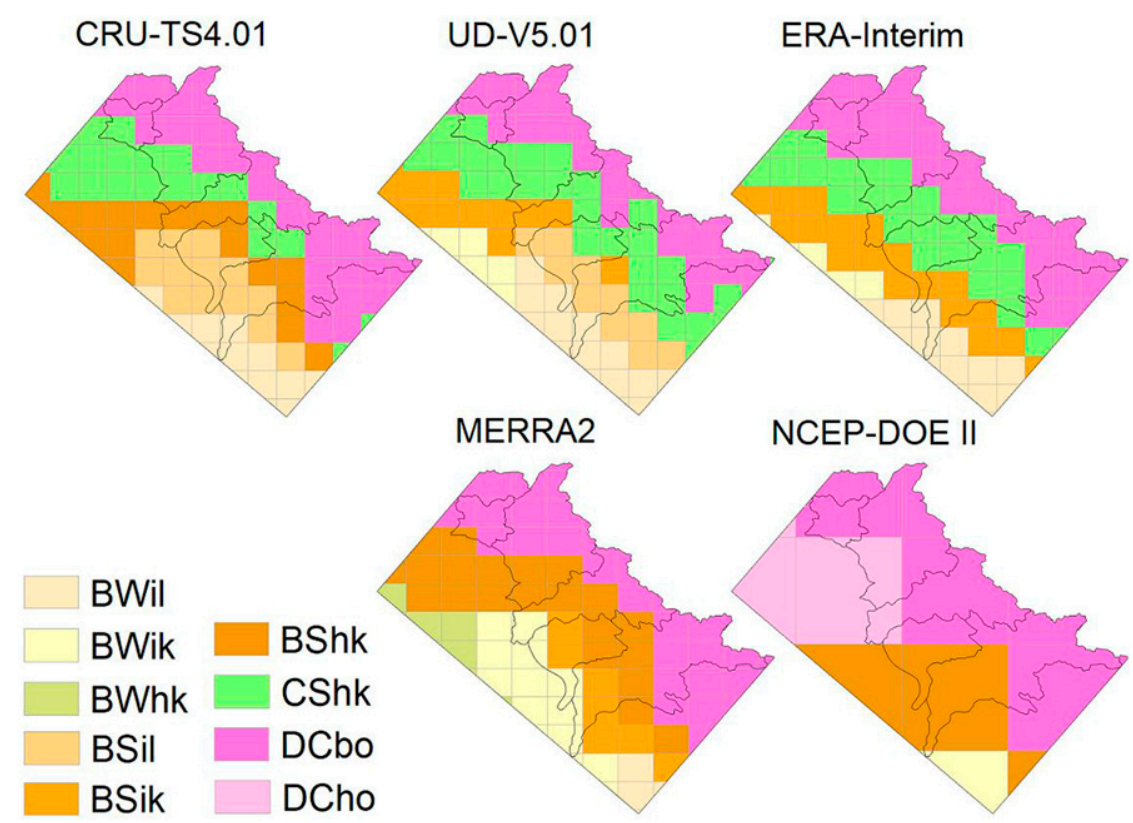

FIG. 5. Köppen-Trewartha climate classification, according to the different datasets for the 1981-2016 period and based on a regular $0.5^{\circ}$ latitude/longitude grid (except NCEP).

reanalysis (Fig. 5). In the latter case, this can be explained by the low spatial resolution of NCEP dataset. However, this does not explain the lack of Cs climates in the MERRA2 dataset, which is characterized by a clear underestimation of winter precipitation relative to some "true level" of seasonal precipitation. In the calculations of Table 3, we saw that the annual precipitation was only $292 \mathrm{~mm}$ according to MERRA2 data, which was $83 \%$ of the nearest amount $352 \mathrm{~mm}$ from the CRU data.

\section{b. Assessment of seasonal precipitation}

The "true level" of seasonal precipitation can be determined in many ways and can provide an idea on the quality of the datasets used. We have seen that one of the main regional landscapes is the moist steppe (Table 2), which receives precipitation levels in excess of $350 \mathrm{~mm}$. In addition, we can compare how bioclimatic landscapes correspond to the map of plant communities presented in Fig. 3c. Figure 6 shows the percentage of area for each land-cover category within the study area as well as within the different areas of the bioclimatic landscapes. Analysis of Fig. 6 leads to two new questions related to the generally accepted geobotanical view of desert and steppe vegetation. First, is not the percentage of grassland area too large $(18 \%-29 \%$ depending on the dataset) that covers the deserts BWil, BWik, and BWhk? And second, is it normal for the landscapes that the CRU, UD, and MERRA2 data classify as steppes, covered with shrubs? The percentage of these shrub steppes (grassy deserts), which are two-thirds covered by vegetation and farmlands, creates the image of moderately moist savannas (dry steppes). This is in line with the earlier description of the Middle East steppe subdivision into moist and dry steppes (Fig. 3 and Table 2). According to
MERRA2 reanalysis, the extreme savannah grids (BShk) are $85 \%$ covered by grassy vegetation, and $4 \%$ - woody vegetation. The average land altitude of $540 \mathrm{~m}$ of this "savannah" corresponds to the heights of Mediterranean climates Cshk according to ERA $(590 \mathrm{~m})$ and CRU $(620 \mathrm{~m})$ datasets. All this indicates a significant underestimation of precipitation in the MERRA2 reanalysis dataset.

Despite the similarities between the observed and estimated vegetation types according to the main climatic zones of the CRU, UD, and ERA datasets, the absolute values of precipitations remain under question. We attempted to assess the mean precipitation limits based on long-term (1931-2010) runoff data of UN-ESCWA and BGR (2013) for the middle to upper basin of each river. Table 4 summarizes the results of this treatment by first determining runoff layers $L$ by dividing the annual runoff volumes $V$ by the watershed drainage areas $A$. Then we compared these runoff layers $L$ with the corresponding maximum value of mean annual precipitation Pmax derived from the different climatic datasets of basin grids. There are five cases in which the Pmax values of MERRA2, CRU, and NCEP were lower than $L$ values, which show "negative" evaporation from the watersheds (see Table 4). The CRU (MERRA2) dataset demonstrates the high river flow coefficient of $92 \%$ for the GZ basin and $85 \%$ for the DY basin. The precipitations of these watersheds also appear to be below the "true level," which means the practical absence of evaporation.

The concept of "true precipitation level" with its apparent conventionality, can help in assessing the quality of other climatological data. Analysis of historical data collected by Davis and Binnie (1959) shows that in the period from 1931 to 1958 , all the important tributaries of the studied rivers became 


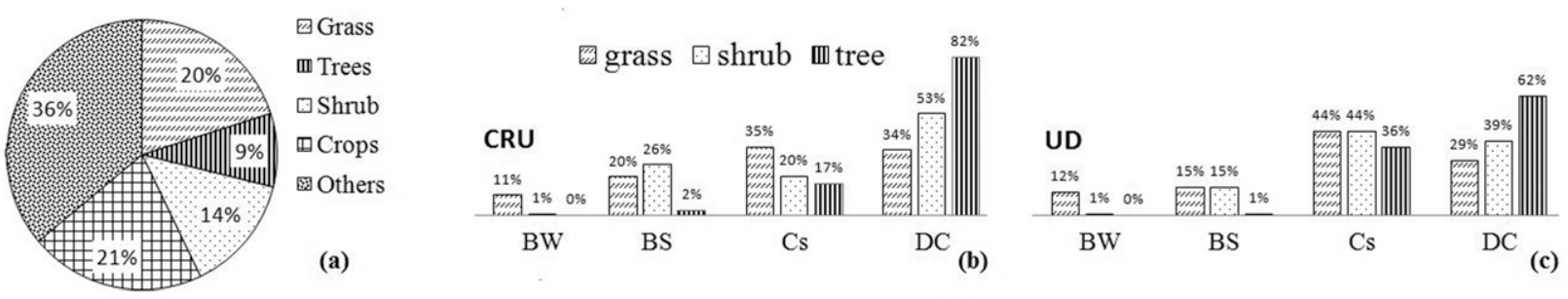

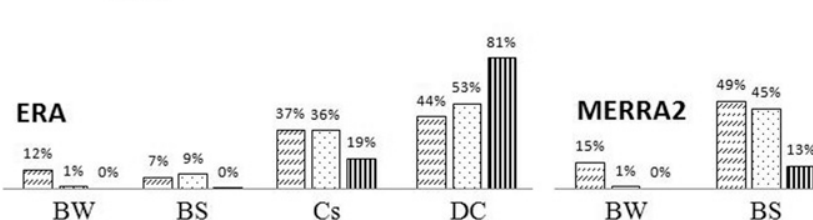

(d)

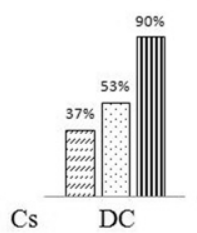

(e)

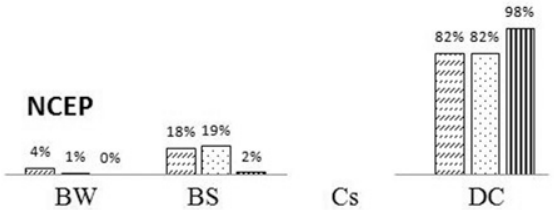

(f)

FIG. 6. (a) Grasslands, shrubs, and forests (trees) coverage of the whole area and (b)-(f) their distributions between the climatic zones according to five datasets.

covered with precipitation observations. From the available stations, we chose only those where rainfall observations were recorded over a period of more than 5 years, and we found 20 stations with altitudes ranging from 200 to $1370 \mathrm{~m}$. We have seen that the precipitation recorded in stations located in areas with an altitude above $\sim 700 \mathrm{~m}$ was significantly higher than those calculated based on the CRU dataset and presented in Table 4. For example, Kirkuk (350 m above sea level) located in AD basin received annual precipitation amounts of $385 \mathrm{~mm}$, while Sulaymānīyah $(880 \mathrm{~m})$ and Halabja $(740 \mathrm{~m})$ in DY basin received 715 and $790 \mathrm{~mm}$, respectively. The rainfall-altitude dependency in the range of 200 to $1400 \mathrm{~m}$, is expressed by an empirical curve [Eq. (2)] built using the least squares method with a Pearson coefficient $r=0.79 \pm 0.18$ :

$$
P(h)=23.99 h^{0,514} \approx 24 \sqrt{h},
$$

where $P(h)$ is the precipitation ( $\mathrm{mm})$, and $h$ is the land height (m). Using Eq. (2), we can estimate the precipitation $P(h)$ based on the average heights of the investigated basins (see Table 4). $P(h)$ shows realistic values of annual precipitation for the FK, GZ, and LZ (DY) basins within the limits of $\pm 10 \%$ $( \pm 20 \%)$ of Pmax derived from ERA and UD data. Only the calculated the true level for the AD basin was within $\pm 20 \%$ of the ERA and NCEP data. Further confirmation of the reliability of our basin-based estimates comes from the fact that this level gives reasonable value for runoff coefficients $L / P(h)$ and increases from the north to the south. At the same time, the average weighted-out runoff in the middle-upper basin area is about $48 \%$, which is more than $39 \%$ of the runoff coefficient estimated at the lower Tigris basin (Isaev and Mikhailova 2009). If we account for the runoff of the remaining low river basins, we can approach the estimates of Isaev and Mikhailova (2009). However, this goes beyond the bounds of the current study.

The above analysis points to a significant underestimation in annual precipitation in three datasets relative to ERA reanalysis and UD observations, which are generally consistent with landscape review and independently estimated values. Over the past 17 years, winter precipitation throughout the region were 320 and $340 \mathrm{~mm}$ according to UD and ERA data, respectively, NCEP and MERRA 2 showed roughly $200 \mathrm{~mm}$, and CRU showed around $260 \mathrm{~mm}$. The mean temperatures according to the examined datasets were also different, but the apparent significant underestimation was only seen in the NCEP dataset: the January to March average regional temperatures over the past 17 years according to the four datasets were in the limits of $6.5^{\circ}-7.8^{\circ} \mathrm{C}$, while it was $1.9^{\circ} \mathrm{C}$ according to the NCEP dataset.

\section{c. NDVI and climate variability (2000-2016)}

In this section of the results, we will first briefly describe the sequence of NDVI images constructed for March and April for

TABLE 4. Assessment of basin hydrometeorology. Boldface font indicates that the Pmax is less than $L$.

\begin{tabular}{|c|c|c|c|c|c|c|c|c|c|c|c|c|}
\hline \multirow[b]{3}{*}{ Basin } & \multirow[b]{3}{*}{ Station } & \multicolumn{2}{|c|}{ Catchment } & \multicolumn{2}{|c|}{ Runoff } & \multirow{3}{*}{$\begin{array}{c}\text { True } \\
\text { level } P(h) \\
(\mathrm{mm})\end{array}$} & \multirow{3}{*}{$\begin{array}{c}\text { Flow } \\
\text { coef } \\
L / P(h)(\%)\end{array}$} & \multirow{2}{*}{\multicolumn{5}{|c|}{ Pmax $(\mathrm{mm})$ on watershed according to }} \\
\hline & & \multirow{2}{*}{$\begin{array}{c}\text { Area } A \\
\left(\mathrm{~km}^{2}\right)\end{array}$} & \multirow{2}{*}{$\begin{array}{c}\text { Height } \\
h(\mathrm{~m})\end{array}$} & \multirow{2}{*}{$\begin{array}{c}\text { Volume } \\
V\left(10^{9} \mathrm{~m}^{3}\right)\end{array}$} & \multirow{2}{*}{$\begin{array}{c}\text { Layer } L \\
(\mathrm{~mm})\end{array}$} & & & & & & & \\
\hline & & & & & & & & CRU & UD & ERA & MERRA2 & NCEP \\
\hline $\mathrm{KH}$ & Zakho & 3500 & 1443 & 2.0 & 572 & 911 & 63 & 764 & 1098 & 911 & 476 & 868 \\
\hline GZ & Eski Kalak & 20500 & 1433 & 12.7 & 619 & 908 & 68 & 668 & 932 & 911 & 400 & 958 \\
\hline $\mathrm{LZ}$ & Dukan & 11500 & 1013 & 6.0 & 522 & 763 & 68 & 458 & 909 & 745 & 300 & 497 \\
\hline $\mathrm{AD}$ & Adhaim & 13000 & 385 & 0.8 & 60 & 470 & 13 & 383 & 718 & 634 & 288 & 401 \\
\hline DY & Derbendikhan & 17800 & 1032 & 4.6 & 258 & 770 & 33.5 & 458 & 909 & 689 & 304 & 497 \\
\hline
\end{tabular}





FIG. 7. Composite NDVI maps for March in 2000-16.

2000 to 2016 (Fig. 7). The purpose of this description is to convince the reader that the spatial distributions of NDVI in March and April reflecting the localization of dry and humid landscapes have large interannual fluctuations due to frequent droughts that overwhelm the vegetation development in the entire lower Tigris basin. We will then confirm this by conducting a correlation analysis between the vegetation indexes for the individual basins, crop yields, and finally with climate variables and global circulation indices for the purpose of finding potential NDVI predictors.

\section{1) VisUAL ANALYSIS OF NDVI}

When visualizing the monthly NDVI distributions, we took into account that most of the region is occupied by arable lands with cereal crops and pastures. Therefore, we based our interpretation on the work of Khalil and Abdullaev (2018) in the description of NDVI values: 0.25 (semidesert sparse vegetation), 0.35 (healthy moderately rarefied farmland vegetation), and 0.4 (dense productive fields of wheat and barley in the maximum biological productivity stage). To enhance the effect, only NDVI pixels with values $\geq 0.4$ were painted in green. In this case, as Fig. 7 shows, the March NDVI maps objectively demonstrate the strong interannual variability of biological productivity of the region. For example, in the spring seasons of 2000, 2006, 2008, 2009, 2011, and 2012 there were virtually no green areas. In fact, during these years, the Tigris and Euphrates basin experienced severe droughts (e.g., Kelley et al. 2015; Muhaimeed and Al-Hedny 2013; Mathbout et al. 2018; Alhumaima and Abdullaev 2018).

On the other hand, the last "green" years of 2013-16 were quite productive according to the agricultural statistics of the Central Statistical Organization (2016). During this period, wheat and barley yields amounted to 44 and 26 hundredweight (h) per hectare, respectively, while during drought periods, these yields of crops were 16 and $12 \mathrm{~h} \mathrm{ha}^{-1}$, respectively. By comparing the locations of bare soil (NDVI of 0.01-0.1) and sparse vegetation (NDVI of 0.1-0.3) pixels during the severe drought years and green years, we can see that drought 

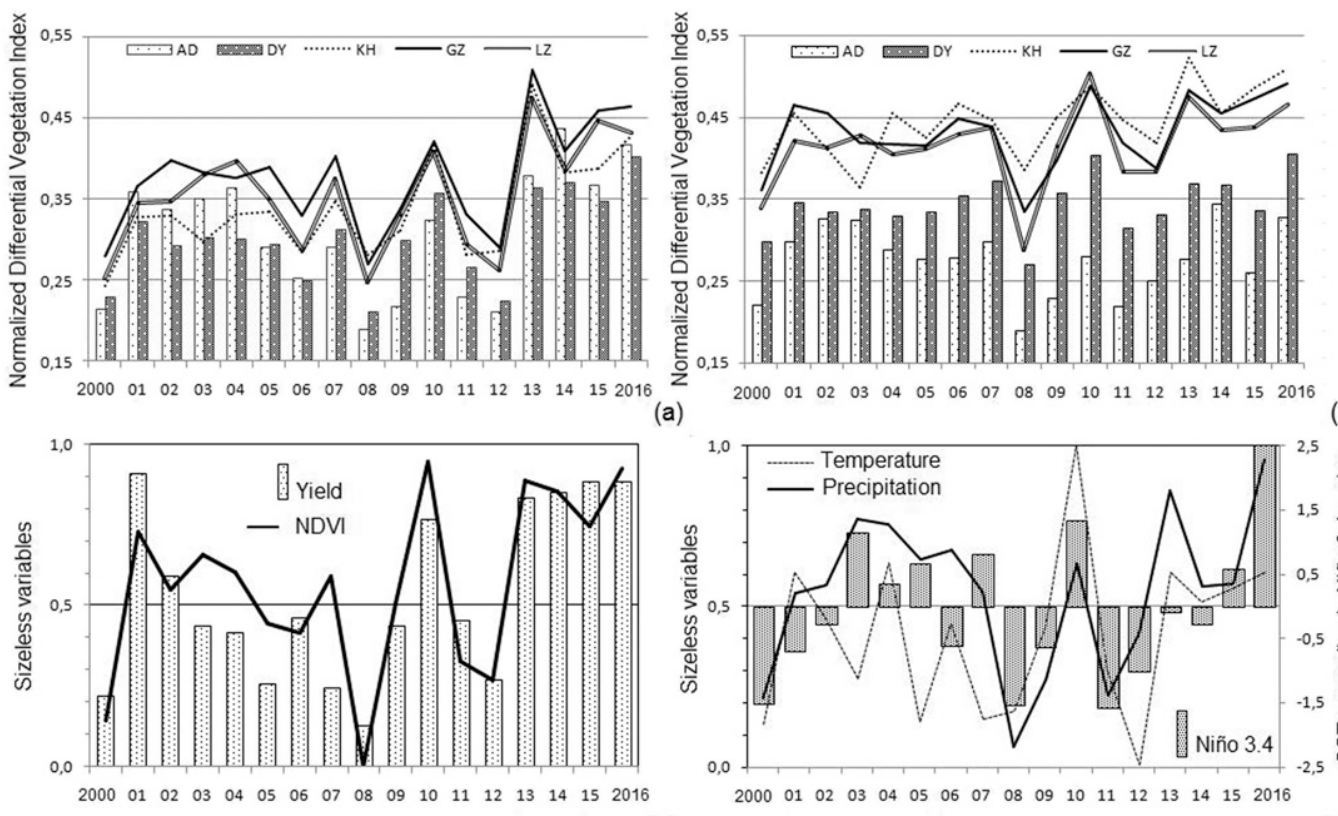

(a)

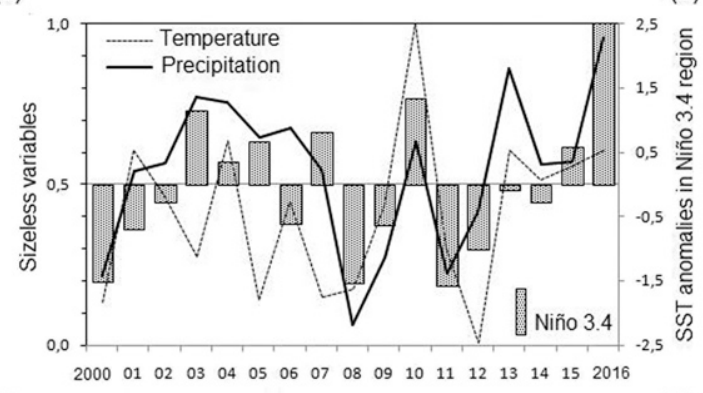

(c)

FIG. 8. Climate variability impacts in the lower Tigris basin: interannual NDVI variability of tributary basins (a) in March and (b) in April, (c) NDVI (line) and cereal yield (bars), and (d) normalized winter precipitation and JFM temperatures (lines) and September-February mean of ocean surface temperature anomalies in the El Niño region 3.4 (bars).

conditions stretch far to the northeast. Thus, most of the regional droughts that negatively affect both natural feed and grain production are caused by large-scale phenomena.

In general, nondrought images in Fig. 7 provide an adequate picture of the region's landscapes. So if we move mentally from the southwest to the northeast and then from the brown desert and gray dry steppes, we will cross the green humid climates of the foothills, and then in the cold mountains we will again see gray tones - the weather is still too cool here in March for the development of most plants. The NDVI pixels with negative values are clear evidence of the March snowpack in upper GZ, parts of upper LZ, and FK highlands.

\section{2) BASIN-BASED NDVI SERIES ANALYSIS}

The above observations on the alternating dry and rainy winters and their effect on all regional vegetation within the river basins were confirmed by the quasi-synchronous course of March and April NDVI (Figs. 8a,b). At the same time, the March NDVI vegetation indices time series (Fig. 8a) have strong-level SRCs $(\geq 0.75)$, with the highest SRC of 0.96 between FK and GZ basins. Strong SRCs of April NDVI vegetation indices (Fig. 8b) were observed between FK, GZ, LZ, and DY excluding moderate correlations $(0.5 \leq \mathrm{SRC}<0.75)$ between FK and DY and between $\mathrm{AD}$ and all other basins.

\section{3) Visualization AND AVERAging OF RANKED VARIABLES}

SRC analysis ensures the independence of estimates from the amplitude of the two related variables by replacing the largest and smallest amplitudes of the time series with their rank. In deciding how to visualize the ranked time series variables without resorting to rank number, we concluded that it can be done through minimum-maximum scaling [Eq. (3)]:

$$
x_{k, \text { scale }}=\frac{x_{k}-\min (X)}{\max (X)-\min (X)},
$$

where min and max denote the minimum and maximum values in $x$ (17 time step variables). From Eq. (3), the positive anomalies will range from 0.5 to 1 , and the negative anomalies will range from 0 to 0.5 . However, in the case of such scaling, it is possible to unify the different sets containing large and small physical values and produce a mean value over these sets without fear of "average temperature over the hospital." Thus, we were able to adequately average the scaled March and April NDVI, and through the same method, we averaged the size-less wheat and barley yields (Fig. 8c) despite the significant difference $(150 \%-200 \%)$ in their amplitudes.

Note that averaging two or more time series makes sense when there is a high correlation between them. In this case, the SRC between the monthly NDVI (March and April) is 0.9 and between the yields of the two crops (wheat and barley) is 0.7 , while SRC $=0.8$ is between the size-less spring NDVI and the combined cereals yields.

\section{4) Possible predictors of NDVI}

When searching for the best possible March and April NDVI predictors, we tried to follow the recommendations of the World Meteorological Organization (WMO) about forecast verification 
(WMO 2010) for six lead times (zero lead, 1-, 2-, 3-, 4-, and 5month leads) for rolling 3-month periods. These periods are marked generally by the name of months [e.g., January-March (JFM)]. Initially, we examined the correlations between the two vegetation indexes with JFM, DJF, NDJ, OND, and SON average temperatures and total precipitations and their combinations, and found that zero-lead JFM average temperatures and zero-lead total winter precipitations (OND + JFM) have the strongest statistical links with the NDVIs according to all datasets. The major SRCs obtained were between March NDVI and both JFM temperatures according to UD $(\mathrm{SRC}=0.80)$ and winter precipitation amounts according to ERA, MERRA2, and NCEP (SRC $=0.75-0.8$ ). The links between NDVI and both temperatures and precipitation from other datasets are characterized by moderate SRC. At the same time, we found that there are strong correlations $(\sim 0.85-0.9)$ between JFM temperatures of all datasets with each other, while the strong correlations $(\sim 0.80)$ between winter precipitations were only found for UD, CRU, and ERA datasets.

The scaling and averaging procedure described above greatly simplified the process of explaining the links between NDVIs and climate variables. The averaged scaled versions of the SPI (ensemble winter precipitation) and $z$ score (ensemble JFM temperature) are shown in Fig. 8d. The droughts of 2000, 2008, 2009, 2012 were associated with relatively cold seasons; the extremely wet winters of 2010 and 2014-16 were predominantly warm. When comparing the seasonal weather combinations, in the five cold and dry winters, the mean March-April NDVI was $0.27 \pm 0.04$; in the six cold and wet seasons it was $0.32 \pm 0.03$, and in the six warm and wet seasons it was $0.36 \pm 0.02$. At the same time, the areas with NDVI values $\geq 0.4$ in March accounted for only $5.6 \%$ of the total study area during the cold and dry seasons, $18.1 \%$ during the cold and wet seasons, and $30.8 \%$ during rainy warm and wet seasons. The combinations of mild and snowy or frosty and snowless winters is common in the study of climatic variability in the steppes and deserts of continental northern Eurasia, but it is very surprising to see this weather in the foothill subtropics closer to the ocean.

Pre the recommendations of (WMO 2010), the dry and rainy seasons were also verified according to the states of ENSO and other global circulations. To visualize active El Niño and La Niña seasons (Fig. 8d), we combined the autumn and winter sea surface temperature (SST) anomalies in the Niño-3.4 region (NOAA 2019b). All of the cold and dry seasons took place during strong La Niña periods (SST $<-1.5$ ). SRC analysis showed that all winter precipitations and both NDVI indices positively react to SON, OND, NDJ, and DJF temperature anomalies of the Niño-3.4 region with $\mathrm{SRC} \approx 0.65-0.70$. Note that the SRC between the ensemble precipitation and the autumn-winter state of ENSO is 0.8.

The results of the ENSO influence are somewhat consistent with the report of Karabörk and Kahya (2009) about the significant ENSO contribution to Turkey's precipitation and rivers streamflows, but contradict with other regional studies (e.g., Cullen et al. 2002; Pourasghar et al. 2019). Cullen et al. (2002) pointed to the strong influence of the NAO to six regional rivers discharge, but we have obtained only weak SRCs between the precipitations and NAO, as well with the NDVIs.
More recently, Pourasghar et al. (2019) indicated that rainfalls in Iran (October-May) are more affected by the IOD than by ENSO. Indeed, we have obtained, respectively, a moderate SRC of 0.7 and 0.55 between March and April NDVI and December month of IOD index, named the dipole mode index (DMI), but these values are almost the same as between NDVIs and ENSO links.

Ensemble JFM temperature responses to the ENSO are weak according to all datasets. However, when looking for links to other global indices, the potential influence of SON states of the AMO to JFM temperatures was discovered with a SRC of 0.6.

In conclusion, the concept of natural borders of large river basins serves as a background to construct the spatially averaged NDVI index, to calculate the ensemble mean of minimax scaled time series extracted from various datasets (Fig. 8), and to correlate these aggregated NDVI and climate variables with global circulation indexes.

\section{d. Landscape sensitivity to climate variability}

Without exception, the landscapes of large river basin can be divided into the landscapes of their principal tributaries and further landscapes of smaller watersheds. In doing so, it becomes necessary to consider ever smaller units, and we see that the landscape responses to climate variability have three components: global, regional, and individual. The response to the global climate variability is demonstrated by Fig. 9, and the sensitivity of landscapes to the regional component is presented on Fig. 10.

\section{1) RESPONSE TO GLOBAL VARIABILITY}

Thus, the spatial distribution of SRC between March NDVI and 4 global circulation indices (Fig. 9) demonstrates that each landscape unit of $0.05^{\circ} \times 0.05^{\circ}$ has its own unique set of responses to the global climate state. As expected, the most positive responses of landscapes were to the ENSO (Fig. 9a) and IOD phases (Fig. 9d). Here, we can see two banded structures of moderate SRCs associated with embedded clusters of landscapes in which the vegetations are subject to the strong influence of SON state of ENSO and December state of IOD. In comparing these fields with similar fields for the following April, it can be argued that these groups of landscapes are hardly random. Despite the difference in scale (see Figs. 6 and 3), the subtropical Cs landscapes (or moist steppes) are most sensitive to ENSO variation, unlike the forest zones of the DC climates, which were more sensitive to IOD variations. However, the response of a group of landscapes is observed in a different form with respect to AMO and NAO. Correlations with these indices are well distinguished by the mountainous steppe landscapes of the GZ and FK upper reaches.

Therefore, landscapes can be classified by their sensitivity to the state of global circulations and highlight geosystems with a predictable response to global climate variability. With all the benefits of such a classification, but it is not physically established, because here we are dealing with so-called teleconnections.

\section{2) LANDSCAPE SENSITIVITY TO REGIONAL CLIMATE VARIABILITY}

Below, we present a more natural approach, including answering the question posed at the beginning of the work about 


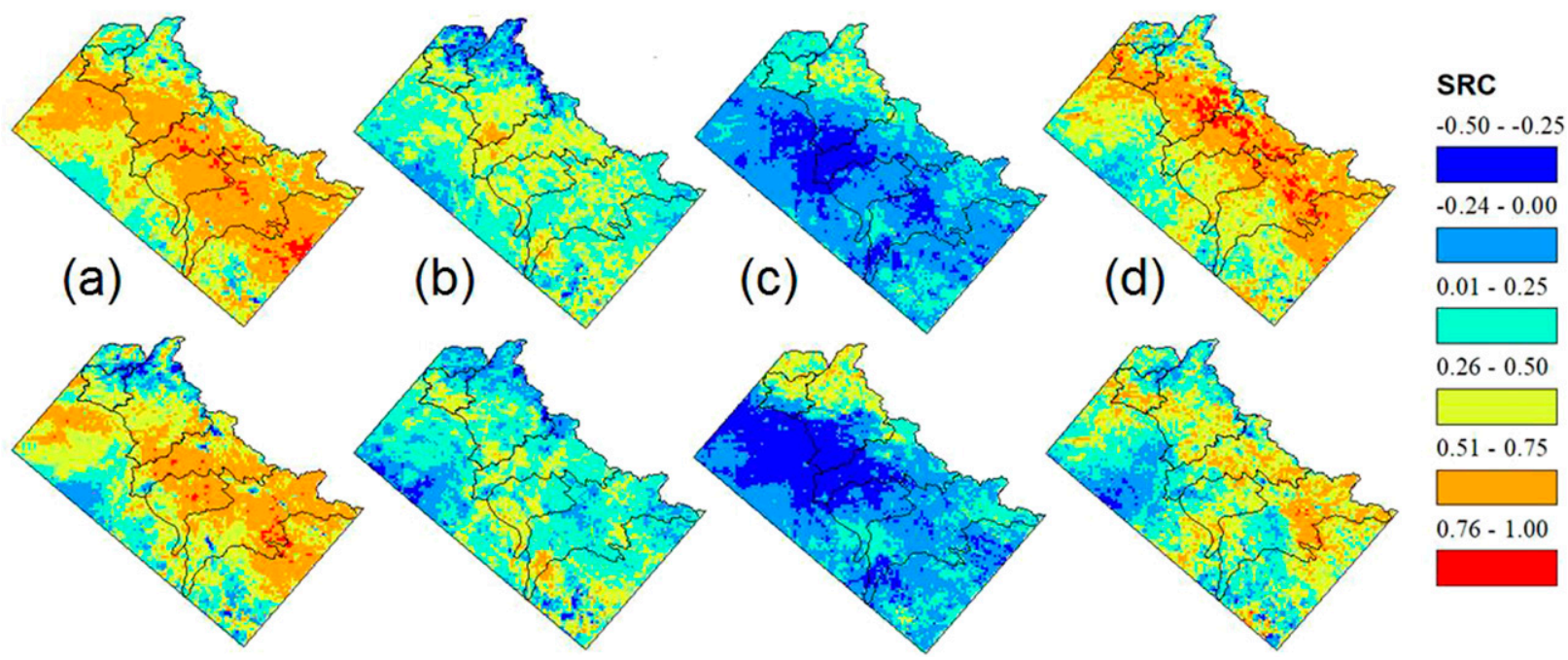

FIG. 9. Distribution of Spearman rank correlation coefficients between (top) March and (bottom) April NDVI and September-October means of (a) Niño-3.4, (b) AMO, (c) NAO indices, and (d) December state of DMI.

the existence of a dataset in which precipitation and temperature variability best reflect space-time NDVI variations. Figure 10 shows the SRC between March NDVI with winter precipitation (Fig. 10a) and JFM temperatures (Fig. 10b). As we can see, the areas with a strong response ( $S R C \geq 0.76)$ to the precipitation of the reanalysis data are larger than those of the observation data. This was somewhat unexpected, especially as two-thirds of the landscapes have a moderate or strong sensitivity to the precipitations generated by the ERA model.
Strong positive correlations are expected between NDVI and JFM temperatures in the northern and mountainous landscapes and SRC distributions are very similar to each other (Fig. 10b). On the other hand, the same landscape may react differently to changes in precipitation and temperature: vegetation may be more sensitive to soil moisture lack than to lack of heat, and vice versa. There may be other cases when water supply and thermal conditions are equally important for the development of individual ecological communities. To

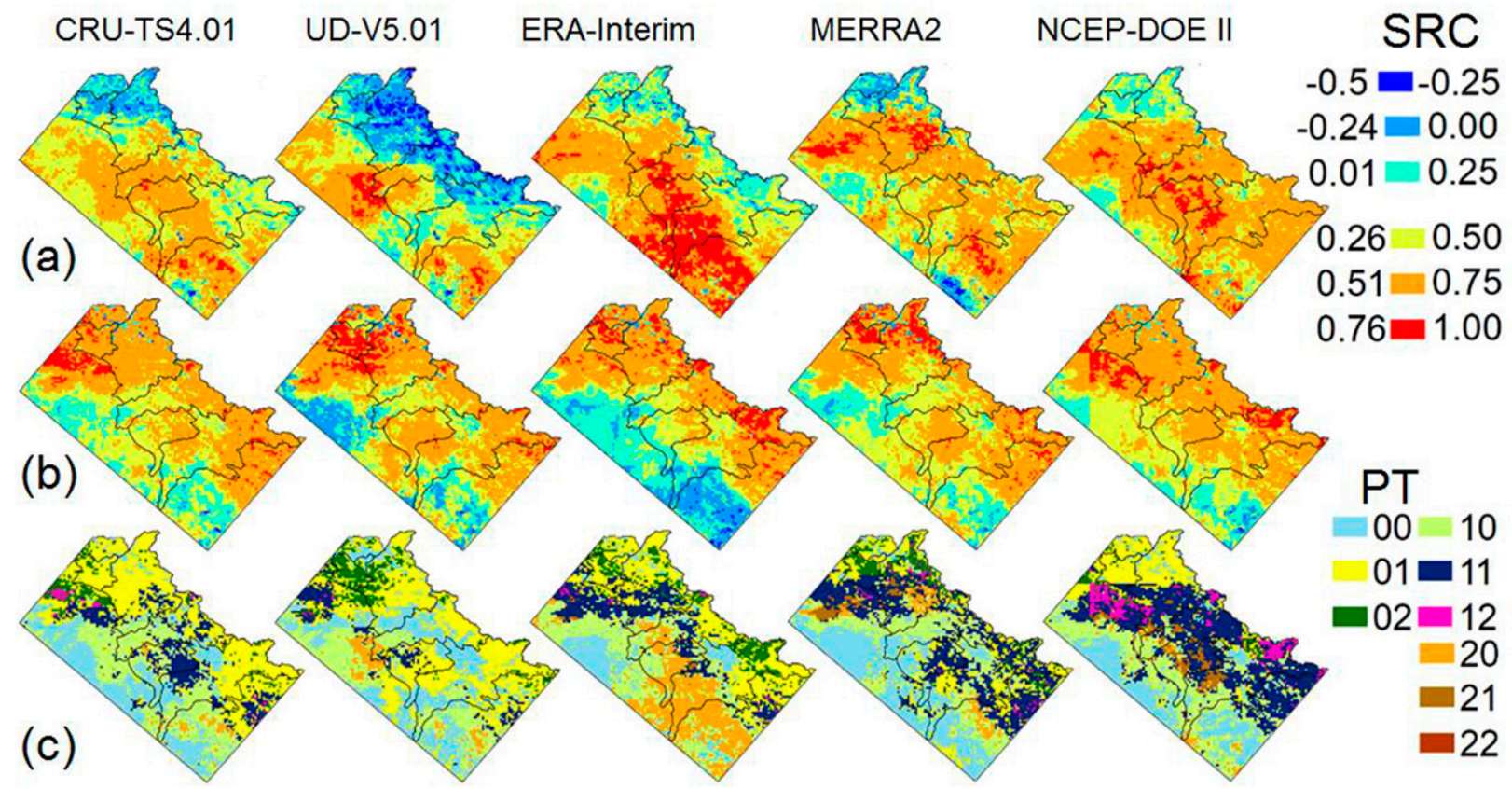

FIG. 10. The response of the basin's vegetation to seasonal weather: spatial disturbance of SRC coefficients between March NDVI and (a) winter precipitation and (b) JFM temperature, according to different datasets. (c) Composite landscape sensitivity to both seasonal $P$ and $T$. The digits 0,1 , and 2 correspond to weak, moderate, and strong responses, respectively. 
visualize these effects, we designed an index to classify landscape sensitivity based on the observed response to seasonal precipitation $P$ and temperatures $T$. First, we categorized the response of NDVI to winter precipitation and JFM temperature as weak negative to weak positive if $-0.5<\mathrm{SRC}<0.5$; moderate positive if $0.5 \leq \mathrm{SRC}<0.75$; and strong positive if $0.75 \leq \mathrm{SRC}<1.0$. We then labeled the weak, moderate and strong responses as 0,1 , and 2 , respectively, and obtained nine pairs of composite landscape sensitivity categories denoted as $00,10,20,01,02,11,12,21$, and 22 where the first digit represents the landscape's response to precipitation $P$, and the second to temperatures $T$. Figure 10 s shows clearly that the assessment of landscape sensitivity is highly dependent on the choice of dataset. Thus, the basin landscapes responses can be characterized as predominantly (i) weak 00 and moderate to $T$ (01) and $P(10)$ based on CRU data, (ii) strong to moisture and weak to heat (20) in the steppe and semideserts landscapes based on ERA data, and (iii) moderate to strong to heat and moisture based on NCEP data.

The difference in the sensitivity of the landscapes to fluctuations in precipitation and temperatures selected from the different datasets (Fig. 10) and the virtually independent spatial distribution of the thermo-hydrophilic landscapes led us to believe that there is no definitive choice when looking for the best dataset that reflects variations in regional biological productivity.

Nevertheless, the existence of spatially consolidated groups of NDVI landscapes synchronized with a specific time series indicates that all of these series contain some temporary natural harmonics of regional climate. The sensitivity categories in Fig. 10c can also be due to the restrictions of correlated variables. Indeed, the response of vegetation to climate variability is influenced by direct and scatter solar radiation fluxes, local topography, soil type, proximity to groundwater, and other geophysical factors that determine the types and life cycles of cultivated crops and wild vegetation. We have only touched upon these issues when describing the ecological regions and vegetation of the basins in the first part of the work. The social reasons of multiyear changes in cultivated areas can also contribute to the SRC level. On the other hand, by developing the hypothesis that each time series reflects hidden information about natural processes in the individual landscapes, there is nothing preventing the use of this hidden knowledge to the NDVI of these landscapes. At the same time, if the two rows of precipitation and temperatures most correlated with the biological productivity of the landscape were chosen from all datasets, then we do obtain a certain answer to which dataset is best, which we have presented in the form of a diagram in Fig. 11. In Figs. 11a and 11b, we demonstrate the areas in which NDVI best respond to precipitation and temperatures, respectively, from certain datasets, while the pie chart shows the contribution of each dataset. The largest areas occupied by the hydrophilic landscapes best respond to the MERRA2-based (36\%) and ERA-based (32\%) precipitation, and the thermodependent landscapes best respond to temperatures derived from MERRA2 (32\%) and UD (23\%). The area of landscapes responding to the MERRA2, ERA, UD, and NCEP data is more than $90 \%$. The percentage of landscapes responding to
CRU data was unexpectedly small (less than $10 \%$ ), because these data are the basis of climate research of the Intergovernmental Panel on Climate Change (IPCC), that is, where small deviations from climate norms are taken into account (e.g., HoeghGuldberg et al. 2018), and as we discussed in the introduction, there is a clear focus in the literature on assessing the impacts of climate change. Perhaps, this anomalously low sensitivity of vegetation to the CRU time series is a side effect of excessively strong thresholds used to remove outliers of precipitation and temperatures during the design of the data reported recently by Harris et al. (2020).

To preassess how the selected sets of temperatures and precipitation series correspond to the actual environmental conditions, we have constructed Köppen-Trewartha bioclimatic landscapes based on this artificial pair series (Fig. 11c). With the exception of one detail, the resulting synthetic landscapes are similar to the existing classifications in Figs. 6a-c, in which all four types of climates-BW, BS, Cs, and DC-have appeared again. Note that Fig. 11c is very close to the bioclimatic landscapes derived from "insensible" CRU data (Fig. 5). Also note that the amount of precipitation in the upper parts of the DY and LZ basins has been clearly underestimated because of the predominance of the MERRA2-based precipitation series (Fig. 11a), which, as we have shown, are half of the flow layer in these basins (Table 4). Taking into account these restrictions, it is possible to present an image of the sensitivity of the landscapes to the synthetic precipitation and temperatures and combine the synthetic hydrothermal index of sensitivity of landscapes (Figs. 11d-f). These figures show that according to the accepted hypothesis, at least one climate series with a moderate correlation (labeled as 01 or 10) with the observed fluctuations of the NDVI can be found for almost all landscapes. Significantly, most landscapes have two of such series (11), or one series but strongly correlated (20 or 02). Some vegetation landscapes have extremely strong links with the synthetic climate variables $(12,21$, and 22).

\section{Conclusions}

Plant communities are components of specific landscapes and are adapted to current bioclimatic conditions. Some general vegetation growth conditions are summarized in the Köppen-Trewartha climate classification, which is based on combination of observed monthly temperatures and precipitation means. Therefore, it would certainly be expected that modern climate datasets would contain time series of temperatures and precipitation that would not contradict these average conditions, at least on a large scale. To test this expectation, and based on the idea of natural landscape boundaries, we choose the Tigris basin as study area, and then took the series of temperatures and precipitation from various gridded datasets and used them as the foundation to create a bioclimatic classification. These results were then compared with the current vegetation in the Tigris basin. To our surprise, only climatic norms from two of five datasets (UD and ERA-Interim) correctly matched the presence of well-known subtropical Mediterranean climates. Our analysis showed that winter precipitation estimates extracted from these two 


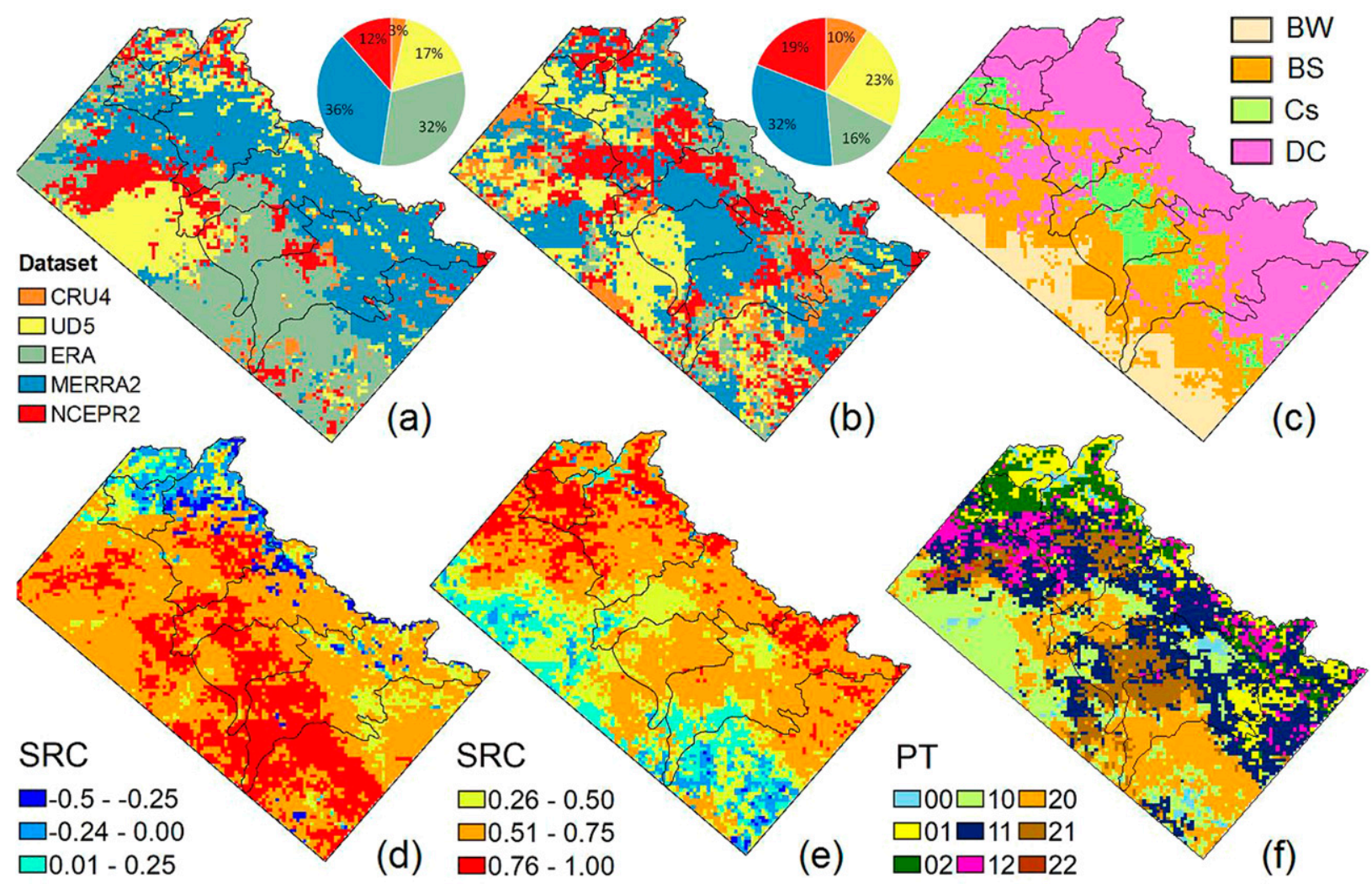

FIG. 11. Landscape responses to synthetic climate data variability: Schematic map of the contribution of different data sources to the synthetic-data-based (a) precipitation and (b) temperatures. (c) Synthetic Köppen-Trewartha bioclimatic landscapes. Spatial disturbance of SRC between March NDVI and synthetic databased (d) winter precipitation and (e) JFM temperature. (f) Landscape sensitivity index to the synthetic climate data variability.

datasets are closest to independent basin-based precipitation estimates. Rainfalls amounts are markedly underestimated by other datasets, especially by MERRA 2 reanalysis, which assigns the dry climate not only to grids corresponding to foothills, but to mountain nodes, as well.

On the other hand, the productivity of the plant communities is sensitive to the climate variability represented by sequences of seasonal weather types. Since NDVI is a proxy for the biological productivity of landscapes, it is natural that the images taken at the end of the growing season (March-April) best show the response to previous hydrothermal conditions: seasonal precipitation from October to March and accumulating temperatures from January to March. Through various techniques of averaging, scaling, and rank correlation, we have discovered a significant response of NDVI and ensemble weather types to the state of tropical circulation. In particular, it is shown that strong La Niña events (cold phase of ENSO) are an indicator of the most severe droughts accompanied by low temperatures throughout the region. The warm and rainy winters are favorable for vegetation abundance, but this weather cannot be so clearly linked with El Niño events. Perhaps here, in addition to ENSO, the IOD plays a role. At the same time, there are different spatial focuses on the impact of these oscillations. Examination of the spatial distribution of landscapes most sensitive to global climate variability showed that foothill landscapes with a Mediterranean climate Cs are sensitive to ENSO state, but the IOD influence extends to predominantly mountainous landscapes with temperate climates DC. It should be said that the third common weather condition of cold and wet winter with intermediate NDVI values do not have any apparent preferences for the phases of global centers of action.

Vegetation, in addition to the common features of a certain climatic zone, has its own individual ecological traces determined by soils, slope exposure, hydrogeology, etc. These ecological features are particularly evident in the fact that the productivity of some plant communities depends mainly on the thermal condition, while others are more limited by soil water. Using this as a concept, we designed a landscape sensitivity map that contained combinations of correlations between NDVI and series of temperature and precipitation from the nearest dataset node. Once again, to our surprise, despite the highly correlated meteorological series among ourselves, we found significant differences in the set of these combinations, ranging from complete nonsensitivity of the landscape to a strong reaction to both meteorological variables. Unlike estimates of average values of precipitation, without a detailed floristic and plant ecology analysis or high-resolution weather 
observations, it is impossible to determine which of the five series of temperatures $T$ and five series of precipitation $P$ are the most accurate to describe the "true seasonal weather." However, if anyone is pragmatic about assessing the quality of datasets, they can select for each point on Earth's surface $P$ and $T$ time series that could be linked strongly with NDVI variability at that point. By making this assumption, we built a map of the sensitivity of biological landscape productivity to synthetic climate variability presented by the best correlated pairs of $P$ and $T$ and found that some datasets are dominant (e.g., MERRA2) or weak suppliers (e.g., CRU) for "properly" oscillating time series. At the end of this study, we can conclude that the study of climate impacts on regional vegetation or other weather-dependent entities must begin with a comparative analysis of various datasets containing meteorological time series to determine the datasets that adequately represent both the climatic norms and interannual and interseasonal weather variability. The landscape approach we have applied can be used for such analysis.

Acknowledgments. We extend special thanks to the editor and to the anonymous reviewers for their valuable comments that helped us to improve the paper. We are grateful to the staff of the South Ural State University/Academic Writing Office for their revisions to this paper.

\section{REFERENCES}

Abdullaev, S. M., O. Y. Lenskaya, and I. V. Gracheva, 2010: Classification and assessment of landscapes condition in the zone of influence of the projected South Ural nuclear electric powerstation (in Russian). Bull. Voronezh State Univ., 2, 60-65.

Alhumaima, A. S., and S. M. Abdullaev, 2018: Preliminary assessment of hydrothermal risks in the Euphrates-Tigris basin: Droughts in Iraq. Bull. South Ural State Univ., 7, 41-58, https:// doi.org/10.14529/cmse180403.

— ence vegetation index forecast by artificial neural network: Example of Diyala River basin. Bull. South Ural State Univ., 19, 5-19, https://doi.org/10.14529/ctcr190301.

Baker, B., H. Diaz, W. Hargrove, and F. Hoffman, 2010: Use of the Köppen-Trewartha climate classification to evaluate climatic refugia in statistically derived ecoregions for the People's Republic of China. Climatic Change, 98, 113-131, https:// doi.org/10.1007/s10584-009-9622-2.

Bao, X., and F. Zhang, 2019: How accurate are modern atmospheric reanalyses for the data-sparse Tibetan Plateau region? J. Climate, 32, 7153-7172, https://doi.org/10.1175/JCLI-D-180705.1.

Belda, M., E. Holtanová, T. Halenka, and J. Kalvová, 2014: Climate classification revisited: From Köppen to Trewartha. Climate Res., 59, 1-13, https://doi.org/10.3354/cr01204.

Blunden, J., and D. S. Arndt, 2019: A look at 2018: Takeaway points from the State of the Climate supplement. Bull. Amer. Meteor. Soc., 100, 1625-1636, https://doi.org/10.1175/BAMSD-19-0193.1.

Central Statistical Organization, 2016: Annual statistical abstract for the years (2000-2016). Republic of Iraq Ministry of Planning, accessed 13 March 2019, http://cosit.gov.iq/en.

Cullen, H. M., A. Kaplan, P. A. Arkin, and P. B. deMenocal, 2002: Impact of the North Atlantic Oscillation on Middle Eastern climate and streamflow. Climatic Change, 55, 315-338, https:// doi.org/10.1023/A:1020518305517.

Davis, C. V., and G. M. Binnie, 1959: Hydrological Survey of Iraq: Summary of Monthly Precipitation at Stations in Iraq, 18871958. Republic of Iraq Developing Board, 62 pp., ftp://ftp. library.noaa.gov/docs.lib/htdocs/rescue/cd024_pdf/005D836E. pdf.

Dee, D. P., and Coauthors, 2011: The ERA-Interim reanalysis: Configuration and performance of the data assimilation system. Quart. J. Roy. Meteor. Soc., 137, 553-597, https://doi.org/ 10.1002/qj.828.

Didan, K., 2015: MOD13Q1 MODIS/Terra vegetation indices 16Day L3 Global $250 \mathrm{~m}$ SIN Grid, version 006. NASA EOSDIS Land Processes DAAC. Subset used: March and April Months, 2000 to 2016, accessed 25 March 2019, https:// lpdaac.usgs.gov/products/mod13q1v006.

Essou, G. R. C., F. Sabarly, P. Lucas-Picher, F. Brissette, and A. Poulin, 2016: Can precipitation and temperature from meteorological reanalyses be used for hydrological modeling? J. Hydrometeor., 17, 1929-1950, https://doi.org/10.1175/JHMD-15-0138.1.

Fernandez, J. P. R., S. H. Franchito, V. B. Rao, and M. Llopart, 2017: Changes in Koppen-Trewartha climate classification over South America from RegCM4 projections. Atmos. Sci. Lett., 18, 427-434, https://doi.org/10.1002/asl.785.

Gelaro, R., and Coauthors, 2017: The Modern-Era Retrospective Analysis for Research and Applications, version 2 (MERRA-2). J. Climate, 30, 5419-5454, https://doi.org/10.1175/JCLI-D16-0758.1.

Ghazanfar, S. A., and T. McDaniel, 2016: Floras of the Middle East: A quantitative analysis and biogeography of the flora of Iraq. Edinburgh J. Bot., 73, 1-24, https://doi.org/10.1017/ S0960428615000244.

Harris, I., P. D. Jones, T. J. Osborn, and D. H. Lister, 2014: Updated high-resolution grids of monthly climatic observations-The CRU TS4.01 Dataset. Int. J. Climatol., 34, 623-642, https:// doi.org/10.1002/joc.3711.

— T. J. Osborn, P. Jones, and D. Lister, 2020: Version 4 of the CRU TS monthly high-resolution gridded multivariate climate dataset. Sci. Data, 7, 109, https://doi.org/10.1038/s41597020-0453-3.

Hoegh-Guldberg, O., and Coauthors, 2018: Impacts of $1.5^{\circ} \mathrm{C}$ global warming on natural and human systems. Global Warming of $1.5^{\circ} \mathrm{C}, \mathrm{V}$. Masson-Delmotte et al., Eds., World Meteorological Organization, 175-311, https:/www.ipcc.ch/site/assets/uploads/ sites/2/2019/02/SR15_Chapter3_Low_Res.pdf.

Isaev, V. A., and M. V. Mikhailova, 2009: The hydrography, evolution, and hydrological regime of the mouth area of the Shatt al-Arab River. Water Resour., 36, 380-395, https://doi.org/ 10.1134/S0097807809040022.

Jamali, S., J. Seaquist, L. Eklundh, and J. Ardö, 2014: Automated mapping of vegetation trends with polynomials using NDVI imagery over the Sahel. Remote Sens. Environ., 141, 79-89, https://doi.org/10.1016/j.rse.2013.10.019.

Kanamitsu, M., W. Ebisuzaki, J. Woollen, S.-K. Yang, J. J. Hnilo, M. Fiorino, and G. L. Potter, 2002: NCEP-DOE AMIP-II Reanalysis (R-2). Bull. Amer. Meteor. Soc., 83, 1631-1644, https://doi.org/10.1175/BAMS-83-11-1631.

Karabörk, M. Ç., and E. Kahya, 2009: The links between the categorised Southern Oscillation indicators and climate and hydrologic variables in Turkey. Hydrol. Processes, 23, 19271936, https://doi.org/10.1002/hyp.7331. 
Kelley, C. P., S. Mohtadi, M. A. Cane, R. Seager, and Y. Kushnir, 2015: Climate change in the Fertile Crescent and implications of the recent Syrian drought. Proc. Natl. Acad. Sci. USA, 112, 3241-3246, https://doi.org/10.1073/pnas.1421533112.

Khalil, Z. H., and S. M. Abdullaev, 2018: Diagnosis of landscapes of the province of Al-Diwaniyah (Iraq) by using of Landsat-8 multispectral images. Vestn. YuUrGU., 7, 5-18, https://doi.org/ $10.14529 / \mathrm{cmse} 180301$.

$\longrightarrow$, and — 2020: Sensitivity of winter crops to climate variability in the irrigated subtropics of Iraq (Al-Diwaniyah). Procedia Comput. Sci., 167, 1066-1079, https://doi.org/10.1016/ j.procs.2020.03.405.

Khan, V., L. Holko, K. Rubinstein, and M. Breiling, 2008: Snow cover characteristics over the main Russian River basins as represented by reanalyses and measured data. J. Appl. Meteor. Climatol., 47, 1819-1833, https://doi.org/10.1175/2007JAMC1626.1.

Kobayashi, S., and Coauthors, 2015: The JRA-55 Reanalysis: General specifications and basic characteristics. J. Meteor. Soc. Japan, 93, 5-48, https://doi.org/10.2151/jmsj.2015-001.

Latham, J., R. Cumani, I. Rosati, and M. Bloise, 2014: FAO Global Land Cover SHARE (GLC-SHARE) database beta-release, version 1.0. Land and Water Division, FAO, accessed 17 February 2019, http://www.fao.org/uploads/media/glcshare-doc.pdf.

Lorenz, C., and H. Kunstmann, 2012: The hydrological cycle in three state-of-the-art reanalyses: Intercomparison and performance analysis. J. Hydrometeor., 13, 1397-1420, https:// doi.org/10.1175/JHM-D-11-088.1.

Mathbout, S., J. A. Lopez-Bustins, J. Martin-Vide, J. Bech, and F. S. Rodrigo, 2018: Spatial and temporal analysis of drought variability at several time scales in Syria during 1961-2012. Atmos. Res., 200, 153-168, https://doi.org/10.1016/j.atmosres. 2017.09.016.

Mazid, A., 2015: Status of wheat production in Kurdistan region of Iraq: Results of baseline survey. Japan International Cooperation Agency (JICA) and International Center for Agricultural Research in Dry Area (ICARDA), accessed 15 March 2019, https://doi.org/10.13140/RG.2.1.1107.3122.

McKee, T. B., N. J. Doesken, and J. Kleist, 1993: The relationship of drought frequency and duration to time scales. Proc. Eighth Conf. on Applied Climatology, Anaheim, CA, Amer. Meteor. Soc., 179-184.

Ministry of Economy, Trade, and Industry/NASA, 2011: ASTER global digital elevation model, version 2. NASA EOSDIS Land Processes DAAC, accessed 15 February 2019, https:// asterweb.jpl.nasa.gov/gdem.asp.

Muhaimeed, A. S., and S. M. Al-Hedny, 2013: Evaluation of longterm vegetation trends for northeastern of Iraq: Mosul, Kirkuk and Salah al-Din. IOSR J. Agric. Vet. Sci., 5, 67-76, https://doi.org/10.9790/2380-0526776.

Nikolayev, V. A., 2006: Landscape Studies: Seminars and Practical Exercises (in Russian). 2nd ed. Moscow State University Press, $208 \mathrm{pp}$.

Nkiaka, E., N. Nawaz, and J. Lovett, 2017: Evaluating global reanalysis datasets as input for hydrological modelling in the Sudano-Sahel region. Hydrology, 4, 13, https://doi.org/10.3390/ hydrology4010013.

NOAA, 2019a: El Niño-Southern Oscillation (ENSO). NOAA Climate Prediction Center (CPC). Subset used: January 1980 to December 2016, accessed 14 October 2019, https://origin. cpc.ncep.noaa.gov/products/analysis_monitoring/ensostuff/ ONI_v5.php.
- 2019b: Atlantic multidecadal oscillation (AMO). NOAA Earth System Research Laboratory (ESRL). Subset used: January 1980 to December 2016, accessed 18 October 2019, https:// www.esrl.noaa.gov/psd/data/correlation/amon.us.long.data.

_ 2019c: North Atlantic Oscillation (NAO). NOAA National Centers for Environmental Information (NCEI). Subset used: January 1980 to December 2016, accessed 21 October 2019, https://www.ncdc.noaa.gov/teleconnections/nao.

— 2019 d: Dipole mode index (DMI). NOAA Earth System Research Laboratory (ESRL). Subset used: January 1980 to December 2016, accessed 30 October 2019, https://www.esrl. noaa.gov/psd/gcos_wgsp/Timeseries/Data/dmi.long.data.

Olson, D. M., and Coauthors, 2001: Terrestrial ecoregions of the world: A new map of life on Earth. BioScience, 51, 933-938, https://doi.org/10.1641/0006-3568(2001)051[0933:TEOTWA]2.0. $\mathrm{CO} ; 2$.

Phillips, T. J., and C. J. W. Bonfils, 2015: Köppen bioclimatic evaluation of CMIP historical climate simulations. Environ. Res. Lett., 10, 064005, https://doi.org/10.1088/1748-9326/10/6/064005.

Pourasghar, F., E. C. J. Oliver, and N. J. Holbrook, 2019: Modulation of wet season rainfall over Iran by the MaddenJulian oscillation, Indian Ocean dipole and El Niño-Southern Oscillation. Int. J. Climatol., 39, 4029-4040, https://doi.org/ 10.1002/joc. 6057.

Reichle, R. H., C. S. Draper, Q. Liu, M. Girotto, S. P. P. Mahanama, R. D. Koster, and G. J. M. De Lannoy, 2017: Assessment of MERRA-2 land surface hydrology estimates. J. Climate, 30, 2937-2960, https://doi.org/10.1175/JCLI-D-160720.1 .

Seddon, A. W. R., M. Macias-Fauria, P. R. Long, D. Benz, and K. J. Willis, 2016: Sensitivity of global terrestrial ecosystems to climate variability. Nature, 531, 229-232, https://doi.org/10.1038/ nature16986.

Taylor, K. E., R. J. Stouffer, and G. A. Meehl, 2012: An overview of CMIP5 and the experiment design. Bull. Amer. Meteor. Soc., 93, 485-498, https://doi.org/10.1175/BAMS-D-11-00094.1.

UN-ESCWA, and BGR, 2013: Inventory of shared water resources in Western Asia. United Nations Economic and Social Commission for Western Asia, Bundesanstalt für Geowissenschaften und Rohstoffe, accessed 17 January 2019, https://doi.org/10.18356/ 48e 4072c-en.

Wartenburger, R., M. Hirschi, M. G. Donat, P. Greve, A. J. Pitman, and S. I. Seneviratne, 2017: Changes in regional climate extremes as a function of global mean temperature: An interactive plotting framework. Geosci. Model Dev., 10, 3609-3634, https://doi.org/10.5194/gmd-10-3609-2017.

Wegmann, M., Y. Orsolini, E. Dutra, O. Bulygina, A. Sterin, and S. Brönnimann, 2017: Eurasian snow depth in long-term climate reanalyses. Cryosphere, 11, 923-935, https://doi.org/ 10.5194/tc-11-923-2017.

Willmott, C. J., and K. Matsuura, 2019: Terrestrial air temperature and precipitation: Monthly and annual time series (19002017), version 5.01. Department of Geography, University of Delaware. Subset used: January 1980 to December 2016, accessed 25 March 2019, http://climate.geog.udel.edu/ climate.

WMO, 2010: Global aspects. Vol. I, Manual on the Global DataProcessing and Forecasting System, WMO Doc. WMO-485, 193 pp., https://www.wmo.int/pages/prog/www/DPFS/documents/ 485_Vol_I_en.pdf.

Zhao, C., and Coauthors, 2017: Temperature increase reduces global yields of major crops in four independent estimates. Proc. Natl. Acad. Sci. USA, 114, 9326-9331, https://doi.org/ 10.1073/pnas.1701762114. 